NBER WORKING PAPER SERIES

\title{
BALLADURETTE AND JUPPETTE: \\ A DISCRETE ANALYSIS OF \\ SCRAPPING SUBSIDIES
}

Jérôme Adda

Russell Cooper

Working Paper 6048

\author{
NATIONAL BUREAU OF ECONOMIC RESEARCH \\ 1050 Massachusetts Avenue \\ Cambridge, MA 02138 \\ May 1997
}

Cooper is grateful to the National Science Foundation for financial support administered by the National Bureau of Economic Research. We are also grateful to F. Maurel, J. L. Madre and D. P., Ministère des Finances for providing some of the data, to João Ejarque and Jon Willis, our research assistants on this project, to Franck Portier for helping us to start this project and to Dan Ackerberg, Paul Beaudry, Olivier Blanchard, Martin Browning, Simon Gilchrist, Sam Kortum, Omar Licandro and Michael Riordan for comments and suggestions. Seminar participants at the January 1996 conference held in Paris on "Should we Rebuild Built-in Stabilizers?," the 1996 NBER Summer Institute, Boston University, McMaster University, Michigan State University, MIT, the University of Michigan, FEDEA, Universidad Carlos III, INSEE, Université de Toulouse and NYU provided helpful comments as well. This paper is part of NBER's research program in Economic Fluctuations and Growth. Any opinions expressed are those of the authors and not those of the National Bureau of Economic Research.

(C) 1997 by Jérôme Adda and Russell Cooper. All rights reserved. Short sections of text, not to exceed two paragraphs, may be quoted without explicit permission provided that full credit, including $\subset$ notice, is given to the source. 
Balladurette and Juppette: A Discrete

Analysis of Scrapping Subsidies

Jérôme Adda and Russell Cooper

NBER Working Paper No. 6048

May 1997

JEL Nos. E62, E65, E21

Economic Fluctuations and Growth

\begin{abstract}
This paper studies the effects of subsidies on durable goods markets. In particular, we study a recent policy in France in which the governments of Balladur and Juppé subsidized the replacement of old cars with new ones. To study this policy, we construct a dynamic stochastic discrete choice model of car ownership at the household level. The resulting decision rules and equilibrium conditions are used to estimate, using aggregate data, the underlying parameters of the model. These policy functions are used to evaluate the short and long run effects of the French policies. We find that these policies do stimulate the automobile sector in the short run but, through the induced changes in the cross sectional distribution of car ages, create the basis for subsequent low activity. Further, while these policies increase government revenues in the short run, revenues in the long run are lower relative to a baseline without intervention.
\end{abstract}

Jérôme Adda

INRA

65 , Boulevard de Brandebourg

94205 Ivry sur Seine

FRANCE
Russell Cooper

Department of Economics

Boston University

270 Bay State Road

Boston, MA 02215

and NBER

rcooper@acs.bu.edu 


\section{Introduction}

This paper investigates the effects of tax credits on purchases of durable goods. In recent years, a number of countries, notably France and Spain, have introduced credits for individuals that scrap old cars and purchase new ones. One motivation for these credits is to promote employment and output in the automobile sector. Our goal in this paper is to understand the output and public finance effects of these policies.

Figure 1 displays registrations of new cars on a monthly basis (seasonally adjusted) for France from 1984 to December 1996. Indicated in the figure are a couple of key policy changes. These include changes in the value added tax on the purchase of new automobiles, as in 1987, 1989 and 1991. In addition, from October 1, 1992 until December 31, 1992, the government offered consumers $2000 \mathrm{~F}$ towards the purchase of a new car to replace a older vehicle. The policy was largely an environmental policy intended to subsidize the replacement of old high pollution cars with new, less polluting ones.

From February 1994 until June 1995, the government offered individuals a payment of $5000 \mathrm{~F}$ for the scrapping of an old car (10 years and older) and the purchase of a new car. ${ }^{1}$ As the average price of a new car in France is about $80.000 \mathrm{~F}$, these subsidies are substantial. From Figure 1, it appears that this policy, termed the Balladur reform, had the desired effect of stimulating new car sales.

In September 1995, the Juppé government announced a scrapping subsidy of 5,000F for small and 7,000F for larger cars for 1 year ending September 30, 1996. Under this policy,

\footnotetext{
'Nole that the policy provides an explicit link between scrapping and buying. This motivates our modeling of the joint decision to scrap an old car and buy a new one.
} 


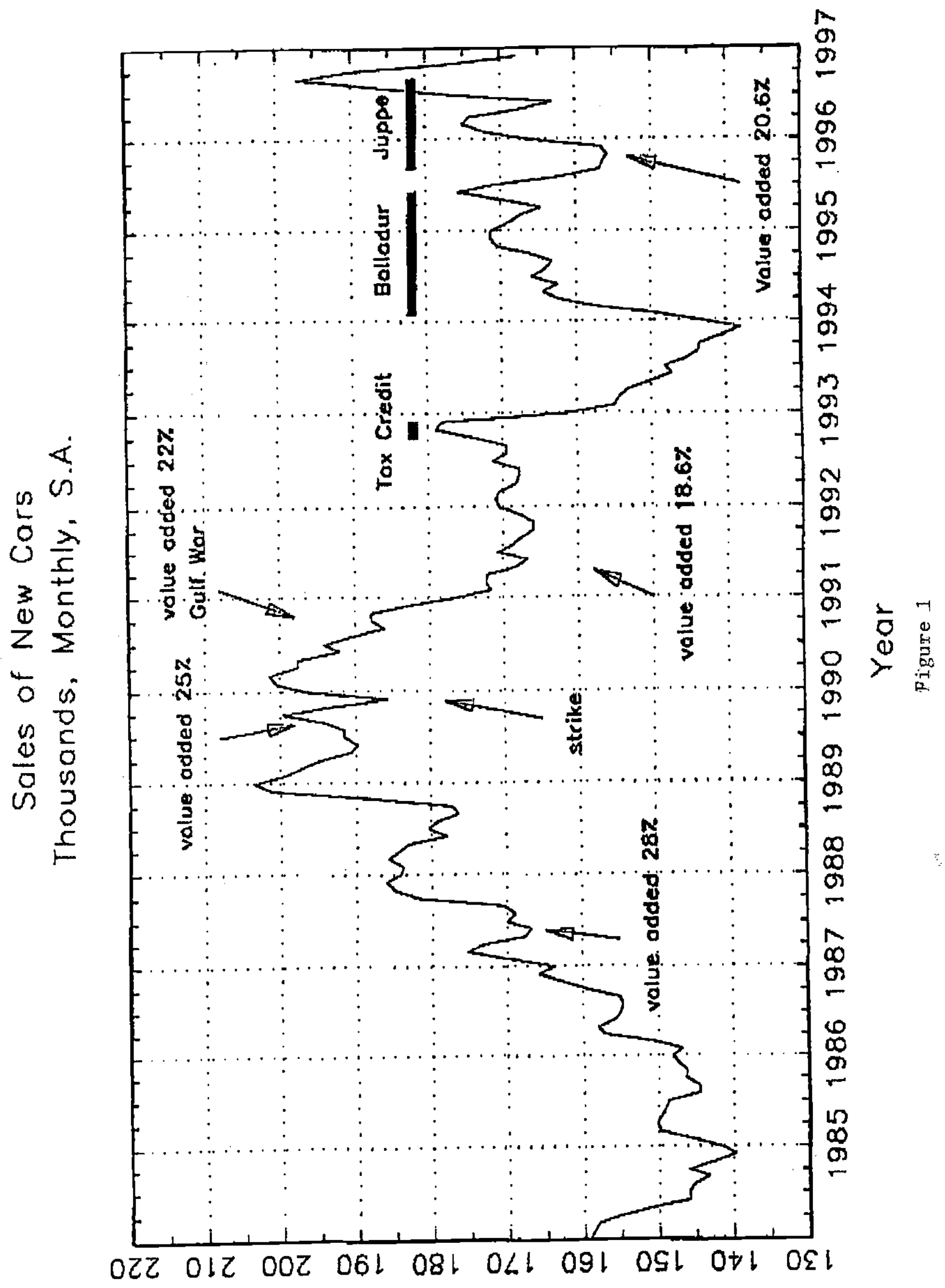


the car had to be at least 8 years old to receive the subsidy. Note that the Juppé policy subsidized the scrapping of younger cars compared to the Balladur reform. Presumably this reflected their understanding that the Balladur reform had created a stock of relatively young cars so that the change in the critical age was necessary for the policy to have a substantial effect.

a. To understand the effects of these policies, we analyze a dynamic discrete choice model at the individual level. Agents are assumed to make a discrete choice regarding the ownership of an automobile: either trade the car for a different one, scrap it or keep it. This decision will, of course, be influenced by the existence of tax policies, such as the tax credits used in France and Spain, as well as car age and other relevant state variables (prices, scrap values, wealth, income, etc.).

Aggregation across individuals determines market demand. This aggregation requires knowledge of the underlying cross sectional distribution of wealth, income and automobile vintages. Thus, changes in the demand for cars arise either through variations in the purchase decision at the individual level or through the evolution of the cross sectional distribution.

We adopt this approach for a number of reasons. First, we find it intuitively appealing to think of durable purchases as discrete choices at the individual level. Bar-Ilan and Blinder [1992] and Lam [1991] provide a variety of arguments for models which rely on discrete adjustments at the microeconomic level. Using a microeconomic data set for the U.S., Lam finds that individual households often make no purchases of cars. These periods of inaction at the microeconomic level are inconsistent with the implications of a representative agent model with convex adjustment costs but form the basis of the discrete choice approach followed in 
this paper. Further evidence is provided in Attanasio [1995] and Eberly [1994].

Second, as suggested by a number of recent papers, changes in the cross sectional distribution of automobile vintage can have a quantitatively important influence on sectoral levels of economic activity. As in Caballero [1993], the interaction of a discrete choice at the microeconomic level and the evolution of a cross sectional distribution might capture the time series of durable purchases. In France, the most recent tax credit, launched by A. Juppé in September 1995, had little initial effect on the purchases of new cars though car sales were quite high by the end of the subsidy period. This may reflect a significant shift in the cross sectional distribution associated with previous policies.

A stylized model is presented in the Section II with an emphasis on the individual's optimization problem. Under the assumption that agents are identical except for the vintage of automobile that they own, we find a price system that clears markets for new and used cars and characterize the optimal scrapping policy.

The final part of Section Il presents an initial policy analysis for our model economy. Policies, such as the Balladur reform, which subsidize the replacement of old cars, operate through the optimal scrapping age. Thus, the initial effects of these policies depend on the fraction of cars older than the (new) optimal scrapping age. The subsequent effects then reflect the evolution of the cross sectional distribution once the policy change has occurred. The idea that the policy will create an incentive to scrap older cars is obvious. The point of doing the analysis is to quantify both the extent of the immediate incentive to replace and the subsequent effects of this policy on sales as the distribution of car ages evolves.

The empirical evidence is summarized in Section III, including data on sales and 
evidence on the cross sectional distribution of car ages in France. Using this information, Sections IV and V presents estimates of the discrete choice model. ${ }^{2}$

Our estimation strategy starts from the dynamic stochastic optimization problem of an individual agent facing uncertainty in prices, income and tastes. Using value function iteration we characterize the policy function at the individual level and, working through the cross sectional distribution, derive moments characterizing the market outcome. The estimate of our microeconomic parameters bring the moments of the simulated model as close as possible to the observed moments. Section IV estimates a version of our model with linear utility, as assumed in the stylized model of Section II, while Section V evaluates a richer model.

The analysis of scrapping subsidies in these last two sections indicates that these policies will boost sales and government revenues in the short run but, at the same time, set in motion variations in the cross sectional distribution of car ages that create long run effects of these policies. In particular, bursts of activity associated with temporary scrapping subsidies are short lived: car production is reduced considerably in future periods. Further, government revenues actually rise when the subsidies are introduced, due to increased VAT revenues, but subsequent reductions in revenues once sales fall are considerable.

II. Individual Behavior and Equilibrium

\section{A. Individual Optimization}

Consider an individual with certain income $y$ in each period of life. The agent obtains utility from the services provided by a durable good (s) and the consumption of a nondurable

\footnotetext{
" As in Rust [1987], our estimation is based entirely on a dynamic replacement problem though, as in Caballero and Engel [1993], we use aggregate data.
} 
(numeraire) commodity $(C)$ with preferences represented by $U(C, s)=C+s .^{3}$ The individual lives forever and maximizes the discounted flow of utility using a discount rate of $\beta<1$.

Each agent can have at most one unit of the durable good at any point in time. Different vintages of the durable good are available in the market: let $i$ index the vintage (equivalently, age) of the good. A new car is of age 1. The service flow from a durable good of age $i$ is given by $s_{i}$. We assume that if $i>j$, then $s_{j}<s_{j}$ : the service flow of a product falls with age. The fall in the service flow with age results from the depreciation of the durable good. ${ }^{4}$ Durable goods of age i sell at a price $p_{j}$. The individual is a price taker in the market. Further, in this initial analysis, there is no uncertainty.

Let $\mathrm{V}_{\mathrm{i}}$ be the value (i.e. lifetime utility flow) of an agent starting a period with a car vintage or age $i \geq 1$. In the analysis that follows, $V_{0}$ represents the value of having no durable good, with $s_{0}=p_{0}=0$. Bellman's equation, which holds for all $\mathrm{i}$, is:

$$
V_{i}=\max _{k \geq 1}\left(s_{k}-p_{k}+y+p_{i}+\beta V_{k+1}\right)
$$

In (1), the agent owns a car of age $i$ which can be sold for $p_{i}$ and a car of age $k$ purchased at price $p_{k}$. This will yield a net income and hence numeraire consumption of $y+p_{i}-p_{k}$ and the service flow of $s_{\mathrm{k}}$ from the durable good that is purchased. This all happens within a period. In addition, the agent begins the next period as the owner of a durable of age $k+1$ and reoptimizes. The agent may also choose to sell the car without buying a new one. This choice

\footnotetext{
${ }^{3}$ The linear utility in the numeraire good mimics an environment in which agents can borrow and lend to smooth consumption. Section $\mathrm{V}$ adds curvature to this problem and studies the role of borrowing restrictions.

This could also represent increased maintenance costs for older cars.
} 
yields consumption of $y+p_{k}$ and $v_{0}$ in the next period. However, as long as there is positive surplus to car ownership, this strategy will be dominated by buying a new car immediately.

A final option of the agent is to scrap the car and receive $\pi>0$ regardless of the vintage. This is taken into account by letting $p_{i}$ denote the market price for a car of age $i$ regardless of its use (scrap or transportation services) by the new owner.

In addition to consumers, we assume that there are competitive firms in the market which supply new products $(i=1)$. For simplicity, let there be constant returns to scale in the production of cars with a unit cost of $c .^{5}$

\section{B. Equilibrium}

An equilibrium is characterized by a price for each age of the durable good and a state contingent policy function for the individual agent such that individuals optimize and markets for each vintage clear. As agents are identical, we focus on an equilibrium in which the only active market is for new goods. ${ }^{6}$ That is, agents will either choose to keep their car or replace it with a new one by scrapping their old car. ${ }^{7}$ Note that this is not really that restrictive: the indifference of agents is consistent with another outcome in which the cars of various vintages are traded. The key is not the trades of used cars per se but rather the decision to scrap an old car for a new one.

With this in mind, the value function assuming that the agent can either keep the car or

\footnotetext{
'This assumplion of constant average costs will be relevant in the estimation of the model since it implies that demand variations will not lead 10 price movements. Further, in contrast to recent work, such as Berry, Levinson and Pakes [1995], we do not consider a differentiated products structure in which firms have markel power. However, our analysis goes through if markups are constant.

${ }^{5}$ From the French data described in Section IIIb, it appears that aboul $45 \%$ of all car sales are new cars.

'So. as in Cooper, Haltiwanger and Power [1995], the ulimate decision is whether or not to scrap the car. Here this is a result of the equilibrium price system rather than an assumption.
} 
scrap it and receive $\pi$ is given by:

$$
V_{i}=\max \left(s_{i}+y+\beta V_{i+1}, s_{1}+y+\pi-c+\beta V_{2}\right)
$$

So the agent either enjoys the stream of services of an age $i$ car and the value of an age $i+1$ car in the next period or scraps the car and purchases a new one at cost c. Implicitly we are assuming that the equilibrium is non-trivial; i.e. car ownership has value so that scraping is followed by the purchase of a new car.

Conjecture an equilibrium price function given by:

$$
p_{i}=s_{i}+\beta\left[V_{i+1}-V_{0}\right]-z \text {. }
$$

In this expression, the constant $\mathrm{z}$ is determined in equilibrium. This price function expresses the price of an age $i$ good as a function of the service flow and the discounted value of the good tomorrow, when it is age $i+1$, relative to the value of having no durable good.

The price function given in (3) and the values given in (1) are interdependent. Solving these two systems simultaneously, using the scrap value of $\pi$, characterizes an equilibrium with no trade. Along the way, we solve for the critical age of a car, denoted by J, such that scrapping is optimal for $\mathrm{i}>\mathrm{J}$.

Proposition 1: At the values and prices given by (1) and (3), agents are indifferent between holding their car of age $i \leq \mathrm{J}$ and exchanging it for another.

Proof: Substituting the price function in (3) into the maximization problem defining $V_{i}$ in (1),

$$
V_{i}=y+s_{i}+\beta V_{i+1}
$$

which is independent of $k$. Hence the owner of a car of age $i \geq 1$ is indifferent between keeping it and selling it for a car of age $\mathrm{k}$. 
The main implication of this proposition is that the markets for cars of intermediate ages will clear without any trade occurring at all. Hence we study the resulting optimal scrapping problem given in (2) independently of the prices for intermediate aged goods. ${ }^{8}$

From that perspective, the price system given by (3) simply supports the no trade restriction found in the optimal scrapping problem. ${ }^{9}$

Proposition 2: If $\mathrm{c}$ is sufficiently low, then there exists an equilibrium in this economy with the price system given by (3) in which there is an active market for new cars.

Proof: From Proposition 1, at the prices given by (3), the markets for all intermediate aged cars will clear. Given this, a sufficient condition for an active new car market is that the value of owning a car is positive.

If the new car market is active, $\mathrm{V}_{0}$, the value associated with having no car at all, is defined by

$$
V_{0}=\max _{k \geq 1}\left(s_{k}-p_{k}+y+\beta V_{k+1}\right)
$$

which, from the price function, equals $\mathrm{V}_{\mathrm{i}}-\mathrm{p}_{\mathrm{i}}$ for any $1 \leq \mathrm{i}<\mathrm{J}$, i.e.

$$
V_{0}=V_{i}-p_{i} \text {. }
$$

That is, the value of having no car at all is the value of having a car of age $i$ less the price of that car on the market. Using (3) and (4),

$$
V_{i}-p_{i}=y+\beta V_{0}+z
$$

which implies

$$
V_{0}=(y+z) /(1-\beta)
$$

Intuitively, (8) means that the value of being in this economy without a car is the discounted value of having income $y$ every period plus the per period surplus of $\mathrm{z}$ from car ownership. Of course, this characterization of $V_{0}$ only makes sense if $z>0$. Otherwise, the car market

\footnotetext{
${ }^{8}$ Though there are no sales of used cars, the price predictions of the model can, in principle, be used in the estimation.

${ }^{9}$ Of course, given all of the indifference in this system, there are also equilibria with active markets for used cars.
} 
will not be active and $V_{0}$ will simply be $y /(1-\beta)$.

By competition in the automobile producing industry, the price of new cars, $p_{1}$, will be equal to the constant production cost of a car, c. Clearly, a sufficient condition for an active car market is $\mathrm{c}$ less than or equal to

$$
\sum_{i=1}^{\infty} \beta^{i-1} s_{i}
$$

which is the value of owning a single car forever.

In equilibrium, values and prices will be monotone decreasing functions of car age:

Proposition 3: $v_{j}>V_{j+1}$ and $p_{j}>p_{j+1}$.

Proof: If $p_{j}$ is decreasing in $j$, then so is $V_{j}$ since, from (6), their difference must be constant. To see that $p_{j}$ must be decreasing, suppose that for some $j, p_{j}<p_{j+1}$. Since $s_{j}>s_{j+1}$, an agent with an age $j+1$ car could sell that car and buy an age $j$ car. This would yield both an increased flow of durable services and higher consumption. In the following period, the consumer could sell the age $j+1$ car for a $j+2$ vintage car and thus return to the original path. The agent has higher payoffs in both periods relative to the equilibrium path of holding the car. Therefore, the no trade equilibrium strategy is dominated. Thus, $p_{j}$ must be monotonically decreasing in a no trade equilibrium.

Using this result, the problem is clearly of the "optimal stopping" variety in that there is a critical age (ignoring the integer constraint) such that cars are scrapped at this age and not before. This can be seen directly from analyzing (2).

Proposition 4: There exists a $\mathrm{J}$ such that the durable good is scrapped at age $\mathrm{J}$.

Proof: From (2), the critical age, denoted by J, such that the agent is indifferent between scrapping and keeping the car for one additional period is given by:

$$
V_{J}=y+s_{j}+\beta\left(\pi+V_{0}\right)=\pi+V_{0} \text {. }
$$

Given the determination of $\mathrm{V}_{0}$ demonstrated above, this leads to the critical age through $\mathrm{s}_{\mathrm{J}}$. From Proposition 3, we know that the $\mathrm{J}$ which satisfies this is unique. Further, for low 
enough $\pi$ relative to $\mathrm{c}, \mathrm{J}>1$.

This proposition implies that there is a deterministic replacement cycle for automobiles: as a function of age, the hazard is 0 until age $\mathrm{J}^{10}$ As discussed in more detail below, there are a number of ways to modify the model to create the scrapping of relatively young cars (due to say car wrecks) and ways to create an active model for used cars through the introduction of additional heterogeneity. Further, introducing some idiosyncratic shocks would create an upward sloping hazard, even at ages less than J. Still, the key to the analysis is the optimal scrapping age $\mathrm{J}$ which, as discussed below, provides the link between policies and the market for new cars."

\section{Policy Analysis in the Baseline Model}

This section of the paper investigates the effects of government policies on the automobile industry. We analyze these effects in the two next subsections using a simulated version of the model with $c=0.6, \beta=.9, y=1, \pi=0.06, \gamma=0.08$ and $s_{i}=i^{-\gamma}$. At this point, these policy exercises are meant to illustrate some properties of the models. In particular, we treat these policy changes as permanent surprises since the model has no uncertainty as of yet. Further, we do not defend this parameterization. An analysis of the policies in a stochastic environment is undertaken in our estimation and policy analysis.

\section{Effect of a Decrease in the Value Added Tax}

The decrease of the value added tax results in a reduction of $p_{1}$ which, from the

\footnotetext{
${ }^{10}$ This is similar to the machine replacement cycle in Cooper-Haltiwanger [1993]. 11 is also clear that the optimal policy is a one sided $(S, s)$ rule though we find the language of hazard functions more convenient. Note that this analysis does not contain a proof of the existence of the values. These values can be calculated directly for any value of 3 .

"In fact, it is for this reason that we have not introduced further heterogeneity into our analysis.
} 
viewpoint of the buyer, is the same as a fall in the cost $\mathrm{c}$. The remainder of the prices are then determined from the conditions for a no-trade equilibrium. Further, even though the cross sectional distribution changes in response to these policies, the equilibrium prices responds to the policies but not to changes in the distribution. This can be seen from the fact that the characterization of the equilibrium prices does not require any information about the cross sectional distribution. This is a very important part of our model as it separates the determination of equilibrium prices from the underlying distribution of car vintages. In this sense, the heterogeneity does not complicate the equilibrium analysis. ${ }^{12}$

The effect of this policy on the sales of new cars will be determined, in our simple model, by the change induced in $\mathrm{J}$, the oldest car. For this parameterization, the optimal scrapping age of cars falls from 11 to 8 . For a $10 \%$ permanent decrease in the VAT, the effects on prices and sales are shown in Figures $2 a$ and $2 b$.

From Figure 2a, the VAT reduction leads to a fall in new car prices and thus raises the value of car ownership. The reduced scrapping age, along with the reduced price for new cars, lowers the prices of all intermediate aged cars.

Figure $2 b$ presents the impulse response of new cars sales. The initial distribution is such that the sales are constant over time, prior to the shock. The shock leads to the value of J to fall and thus sales of new cars to rise. As the shock is permanent, sales return to their original level in the period after the shock. This property of the simulation arises from our assumption of an uniform initial distribution across the 11 ages. Note from the simulation,

\footnotetext{
1: This is another consequence of our constant cost assumption.
} 


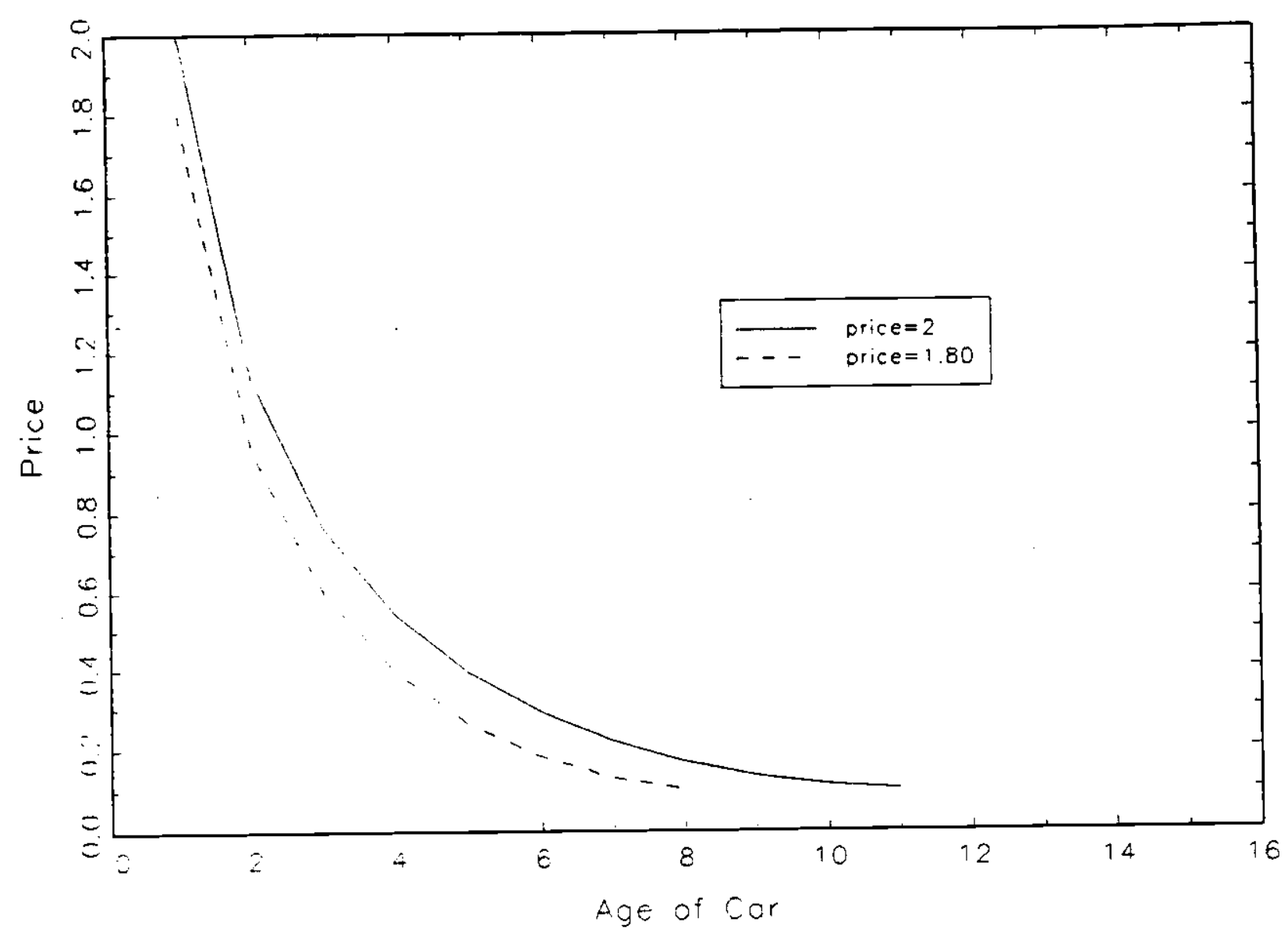

Price Effects of a VAT Reduction

Figure $2 \mathrm{a}$ 


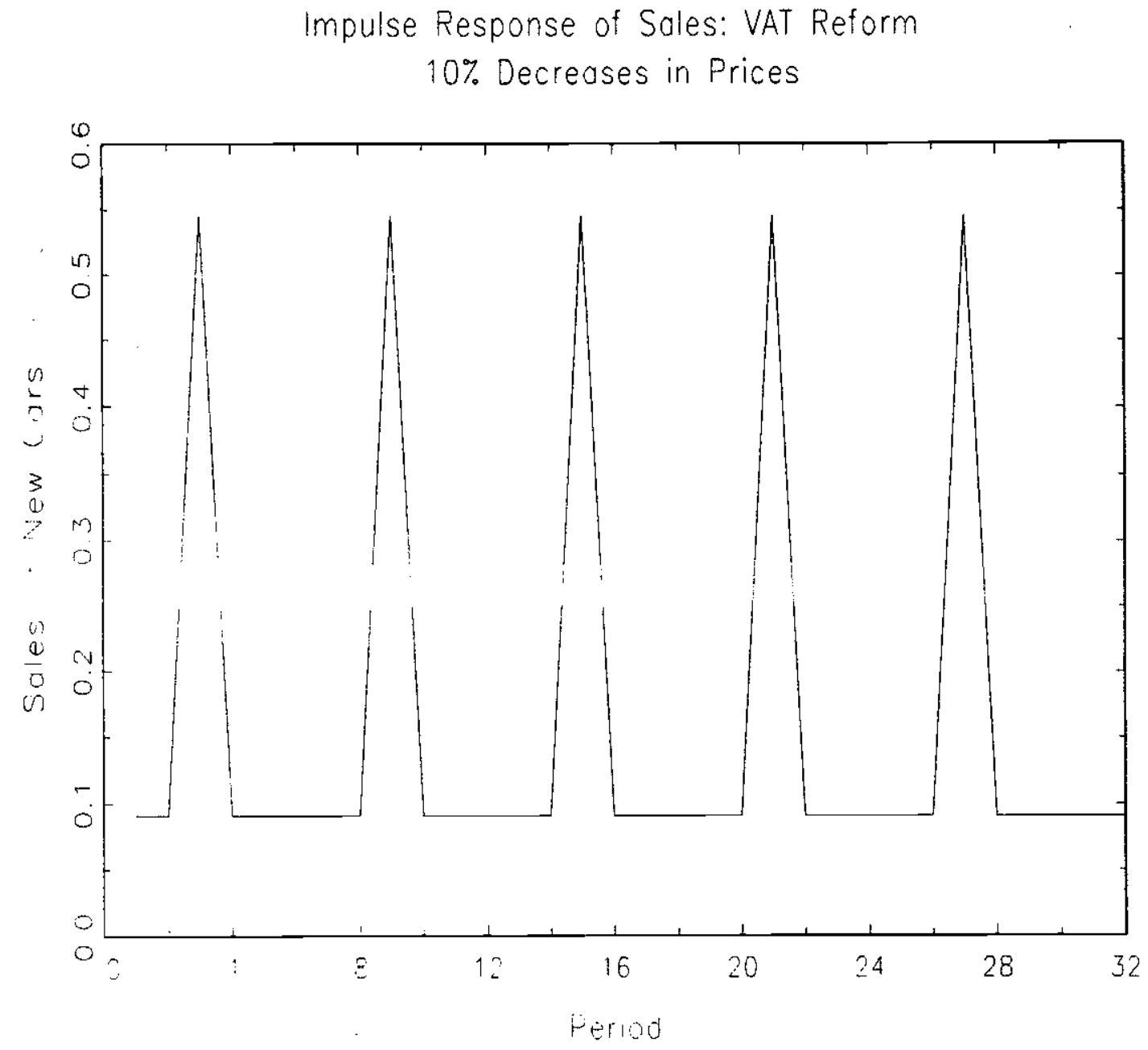

Sales Effects of a VAT Reduction

Figure 2b 
that the burst of sales in response to the policy reappears every eight years. These "echo" effects are an important component of our model as they reflect the evolution of the cross sectional distribution of car ages. ${ }^{13}$

\section{Balladur-Juppé Reforms}

To model this policy, we consider the effects of a change in the scrap value for cars, $\pi$. In equilibrium, this policy will influence the prices of all cars, the scrapping age and thus the purchases of new cars. For our simulated economy, the implications for new car purchases are the same as in Figure $2 \mathrm{~b}$. In both cases, the scrapping age falls by the same amount and new sales follow the same path since consumers respond to the net price of a new car.

Figure 3 illustrates the effects of the policy on prices. Note that the effect of a VAT decrease and of a scrapping subsidy have qualitatively different effects on the prices. The tax credit has no effects on the price of new cars since competition forces $p_{1}=c$. With the increased subsidy, intermediate aged cars have more value since they will ultimately receive a higher scrap value.

Overall, three key points emerge from the simulations. First, the optimal scrapping age falls in response to either a reduction in the VAT or an increase in the scrapping subsidy. The response of sales reflects both the change in the optimal scrapping age and the shape of the cross sectional distribution at the time of the policy. Second, increasing the scrapping subsidy (VAT) will cause prices of intermediately aged cars to rise (fall). Third, the evolution of the system will include replacement cycles. The magnitude and duration of these cycles

${ }^{13}$ These echo effeets are described in Bar-llan and Blinder [1992] and more recently by Boucekkine and Licandro [1996]. 


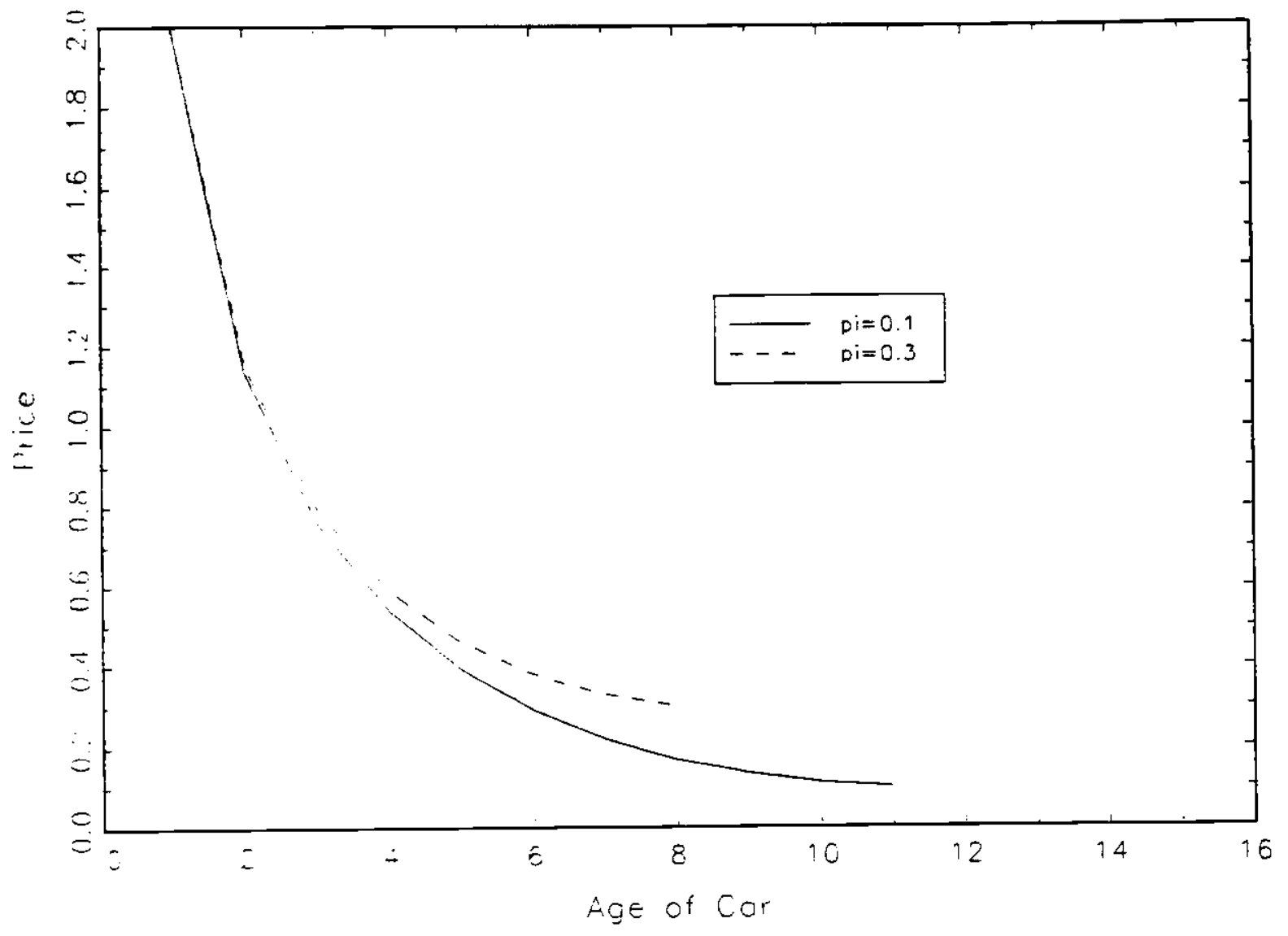

Price Effects of an Increased Subsidy

Figure 3 
will depend on the initial sales response, the permanence of the policy and the presence of exogenous depreciation.

\section{Empirical Evidence}

\section{A. Aggregate Data}

Figure 1 shows the time series of new car sales (monthly, seasonally adjusted, in thousands) in France between 1984 and December 1996. The data are collected by the INSEE, the French statistical institute. The data indicate the fairly large movements in automobile sales over this period. These are partially due to the various policies that have altered the costs of new cars as well as more aggregate variations, such as the recession in France in 1992-93.

The cross sectional distribution of cars in France, annually for the years 1972 through 1995 is also collected by INSEE from household surveys. These data are shown in Figure 4 and indicate, by year, the fraction of cars of each age.

There are two noteworthy aspects of the cross sectional distribution. First, there appear to be substantial variations in the cross sectional distribution over time. In the context of our model, this represents an important source of variation in consumer demand for cars. Over this sample period, both the average age (Figure 5a) and fraction of cars under age 5 (Figure 5b) show significant variation.

Second, it is possible to follow large movements in sales as they influence the cross sectional distribution through time. So, for example, there are large reductions in sales in 1975 and 1985-86 which, from Figure 4, appear as valleys in the evolution of the cross sectional distribution. Likewise, the cross sectional effects of the burst of sales around 1989 


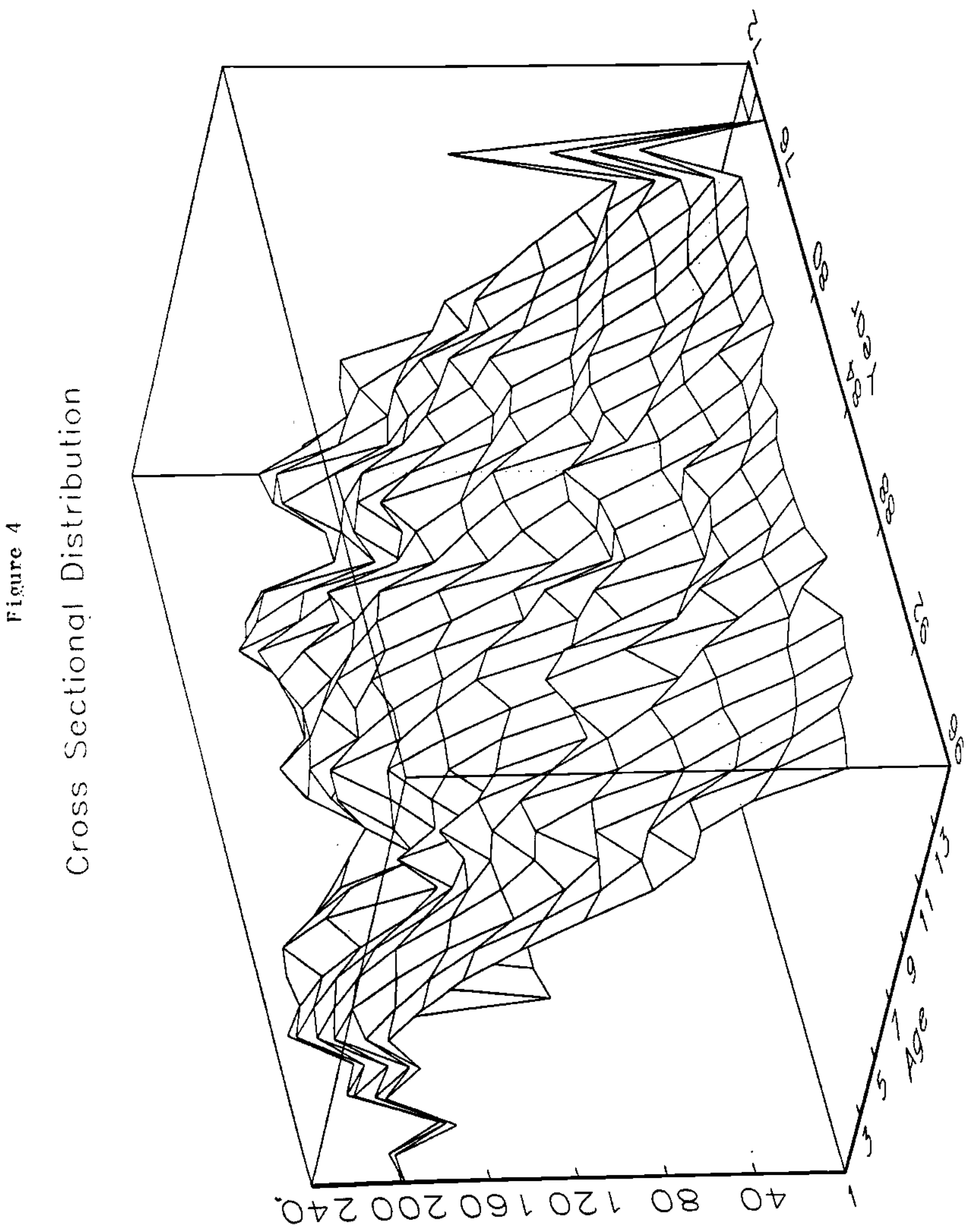




\section{Small Cars}

\section{Quantities and Fraction under Age 5}

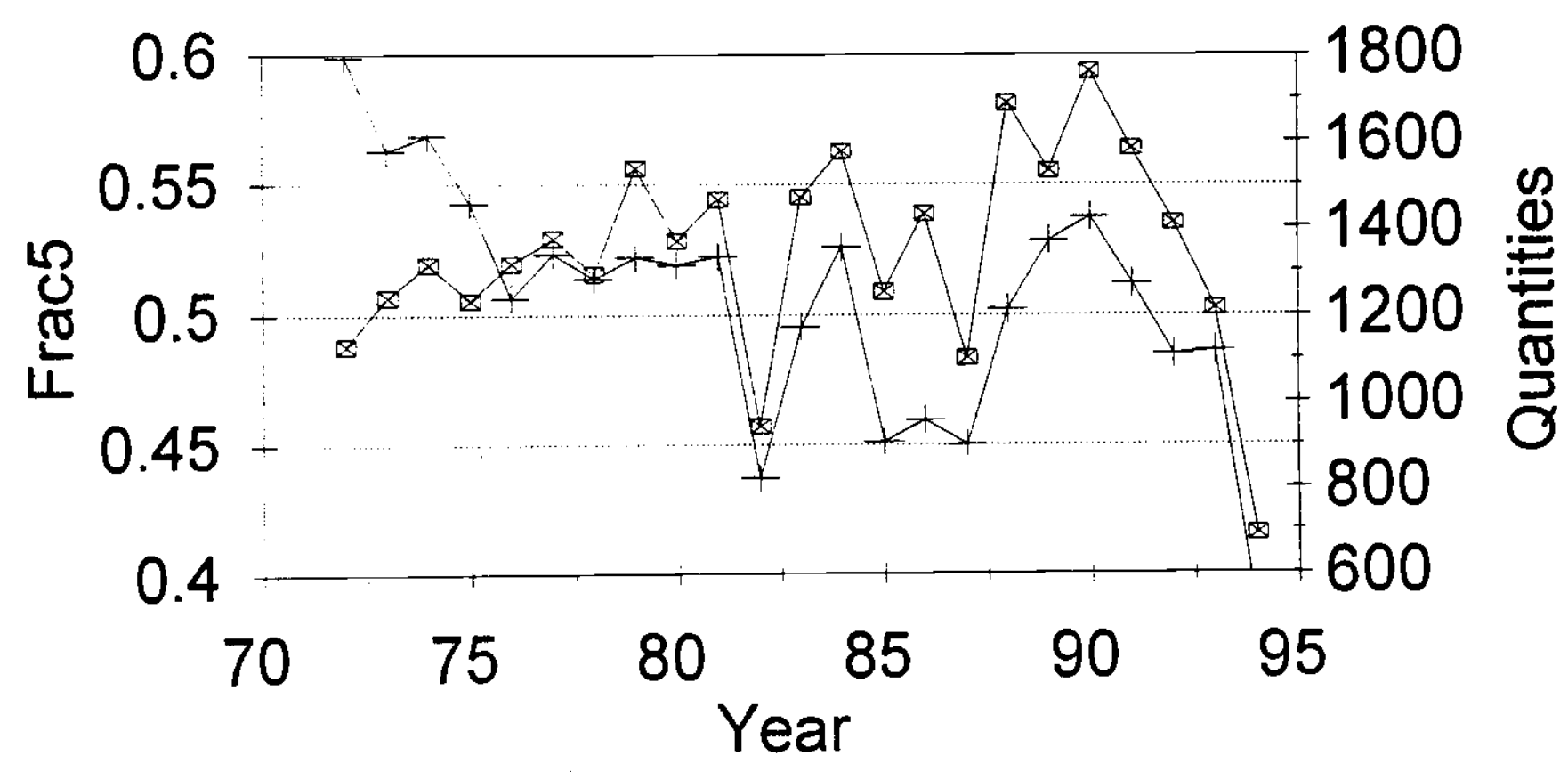

+ Frac5 $*$ Sales 


\section{Small Cars}

\section{Quantities and Average Age}

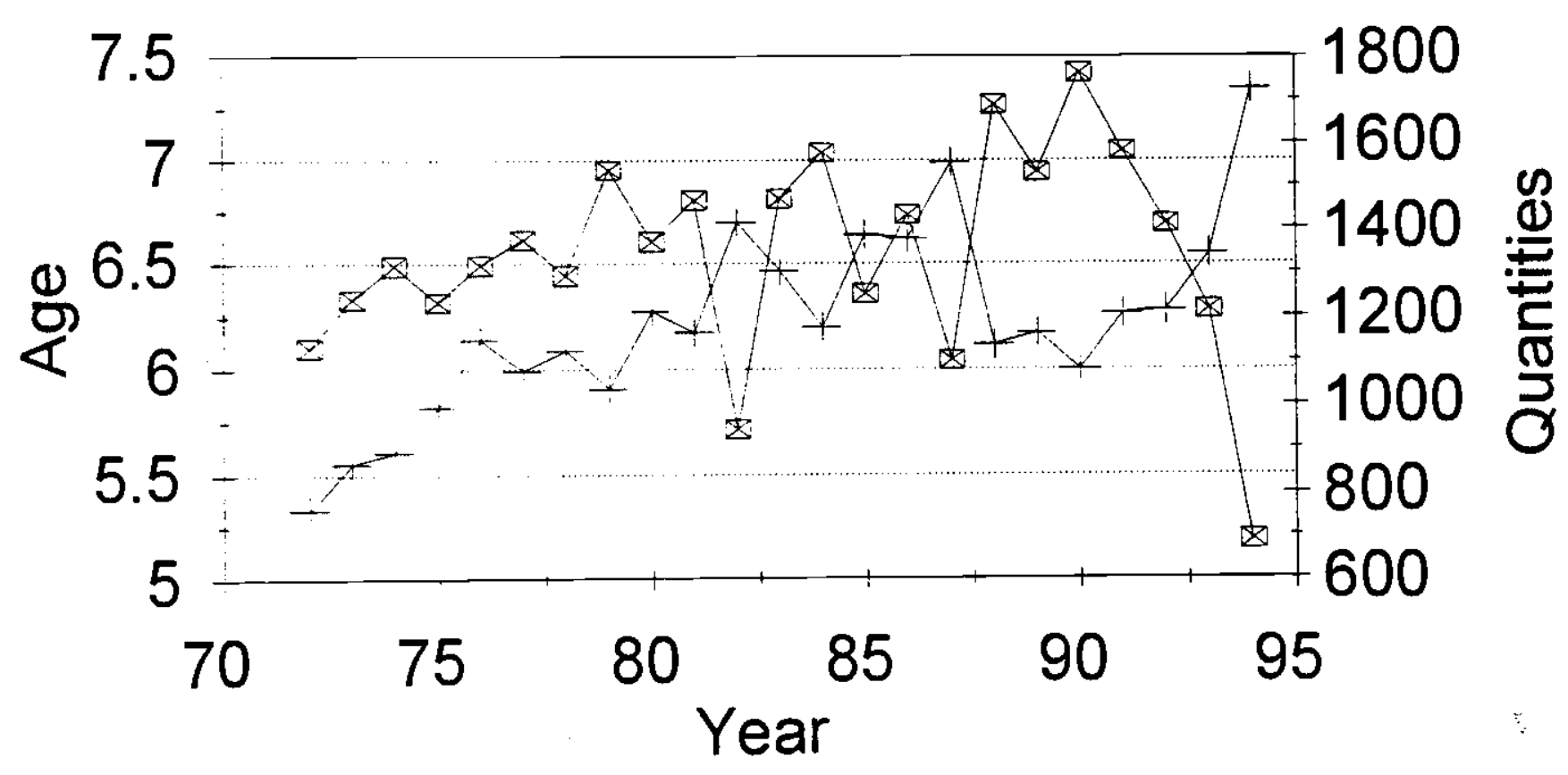

+ Average Age $\star$ Sales 
can be seen as well in Figure 4. The burst of sales leads to an increase in the fraction of cars under age 5 and a reduction in the average age of cars.

The cross sectional distribution can be used to "back out" the true hazard function for each year. ${ }^{14}$ Let $H_{t}(i)$ be the probability that an age $i$ car is scrapped in period $t$ : i.e. the period $t$ empirical hazard function. Further, denote by $G_{t}(i)$ the fraction of age $i$ cars in period t. Then the hazard and the cross sectional distribution are linked by:

$$
G_{t+1}(i+1)=\left(1-H_{t}(i)\right) G_{t}(i)
$$

The average hazard for the $1972-96$ period is slightly increasing until about 10 years, averaging less than $10 \%$, which we interpret as scrapping due to car wrecks. The average hazard then rises significantly after age 10 to nearly $50 \%$ by age 20 .

\section{B. Micro Data}

The micro data is drawn from the French "Enquête de Conjoncture auprès des Ménages" at INSEE. It is a cross-section dataset surveying around 6000 households a year from 1972 to 1994. It contains information on the ages of the automobiles, their dates of purchase, their model types and their prices as well as information on household income and demographic structure. The data set has a partial panel structure as it reports information on households during two consecutive years, from 1977 to 1987.

The panel structure of the database allows us to analyze the pattern of expenditure for cars. Approximately $20 \%$ of the households replace their cars each year. Conditional on

\footnotetext{
${ }^{14}$ Here though one must be careful in that the cross sectional distribution is in terms of fractions of cars and the total number of cars changes each year. Correcting the hazard to account for changes in the stock of cars has only minor effects on our results. See Gautier and Rouchet [1995] for additional details on survival functions for French cars.
} 
replacing a car, more than $45 \%$ of the households buy a new one. The percentage of households buying a particular other vintage is never higher than $7 \%$, decreasing with the age of the car. These figures are obtained for the pooled sample on the years 1977 through 1987. Conditional on selling a car, there is no clear age at which the household sell their car, at least in the pooled data. The peak is from three to seven year old cars.

As a first attempt to model the purchase of automobiles, we ran a probit regression for car replacement using this micro data. ${ }^{15}$ We relate replacement to the age of the car, the age square, the income and the squared income of the household as well as a set of dummies for low state of prices for new cars, crossed with the type of car owned. The control variables include dummies for the type of the car, the age of the head of household, the number of children, the number of working members in the household, education, as well as year dummies. The price for scrapped cars is not in the set of control variables as this is not contained in the dataset.

The results are presented in Table 1 . The probability of replacement is significantly increasing in the age of the car, as well as the income of the household. The prices being low are also a determinant of automobile purchase. As shown in Table 1, low state of prices has a positive effect on the probability of replacing a car, except when considering the prices of large cars. The estimated hazard, the probability of replacement as a function of age given that other variables are at their mean values, is shown in Figure 6.

These results support our modeling in that both age and prices are important in the car

\footnotetext{
${ }^{15}$ Strictly speaking, here replacement means the selling of a car. But, purchases of cars over 5 years old are only about $20 \%$ of car purchases: most sales appear to be followed by new purchases.
} 


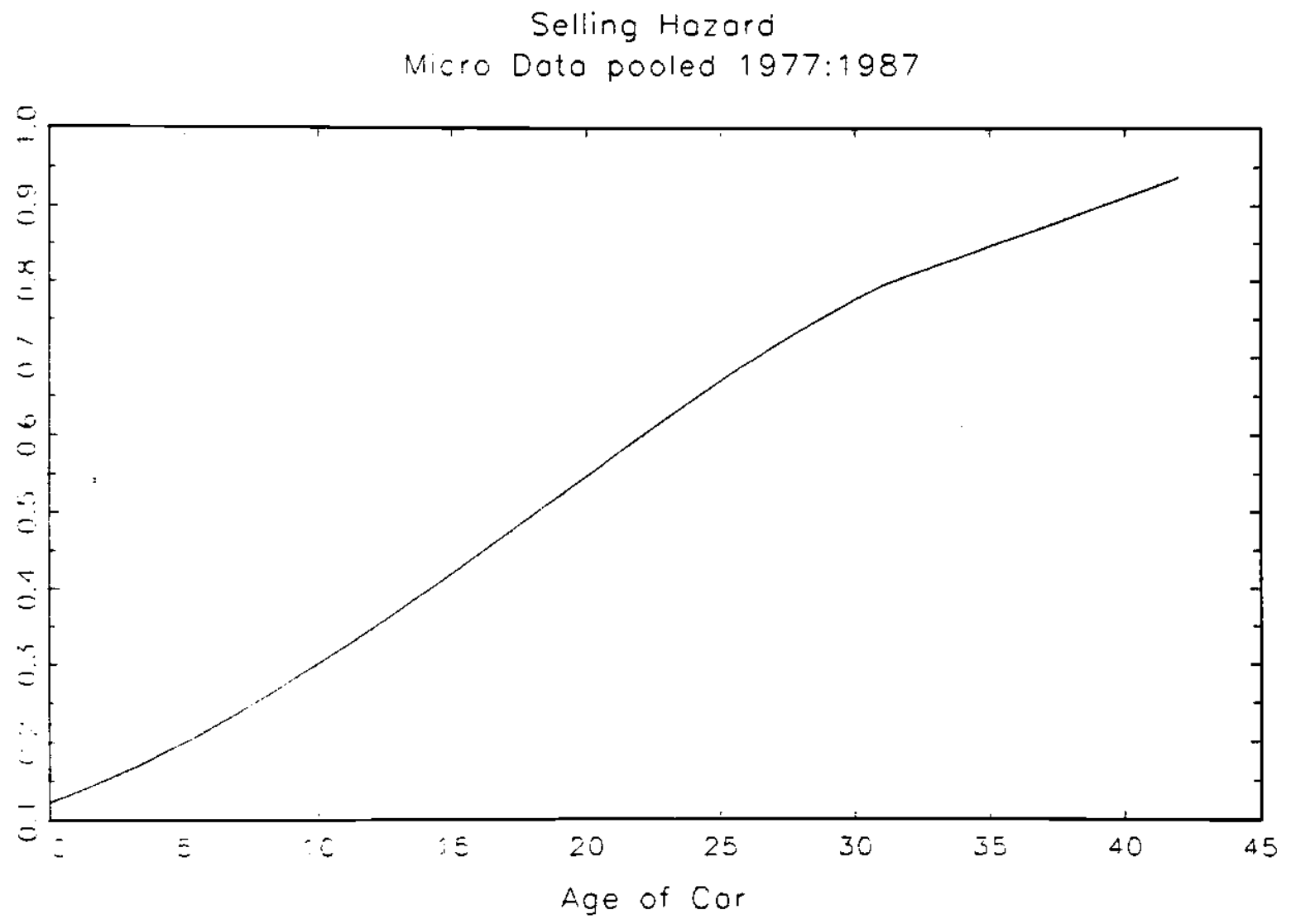

Figure 6 
replacement problem. In particular, the probability of replacement is an increasing function of age. Most often, the households buy a new rather than used car.

\section{Estimation and Policy Analysis}

For the exercise of evaluating the impact of scrapping policies, a less structural approach (such as the above probit analysis) is inadequate since there is no precedent for these policies. So, our approach is to estimate the structural parameters of the model using data prior to the policies. Given these parameter estimates, an analysis of the policy is feasible.

\section{A. Overview of General Estimation Strategy}

The starting point for the estimation is to characterize the underlying economic environment (preferences, technology, exogenous stochastic processes, etc.) through some vector of parameters denoted by $\theta$. For a given value of $\theta$, we solve the dynamic programming problem at the individual's level. As before, the solution to the dynamic program of the agent is a state contingent optimal scrapping age denoted by $J_{\theta}(z)$. Here $z$ represents the state vector of an individual agent which could potentially include aggregate variables (prices, income, scrapping values) as well as idiosyncratic shocks to tastes and income. The hazard function at the individual level, $h_{\theta}(i, z)$, is a step function of $z$ and car age $\mathrm{i}$ : $h_{\theta}(i, z)=\delta$ if $i<J_{\theta}(z)$ and $h_{\theta}(i, z)=1$ if $i \geq J_{\theta}(z)$.

At the aggregate level, the idiosyncratic components of the state will be averaged out leaving a hazard function that depends on the state of aggregate income, prices and aggregate taste variations and car age, denoted by $h_{\theta}(i, Z)$, where $Z$ is just the component of $z$ that is common to all agents. While the hazard at the individual level is a simple step function, the 
aggregate across individuals will yield an upward sloping function of car age: as age increases the fraction of agent whose idiosyncratic shocks will lead to scrapping will increase.

Let $G_{t}(i)$ be the number of cars of age $i$ in period t. Aggregate sales $\left(S_{V}\right)$ and the cross section distribution of cars evolve as:

$$
\begin{aligned}
& S_{t}=S_{\theta}\left(Z_{t}\right)=\sum_{i=1}^{\infty} h_{\theta}\left(i, Z_{t}\right) G_{t}(i) \\
& G_{t+1}(1)=S_{t}, G_{t+1}(i+1)=\left[1-h_{\theta}\left(i, Z_{t}\right)\right] G_{t}(i) \text { if } i \neq 1
\end{aligned}
$$

Through this construction, we have a link between the parameter vector $\theta$ and aggregate observables: sales and the cross sectional distribution.

For estimation, the model is simulated using draws from the underlying stochastic processes. A series of statistics are then computed from these simulations (such as the correlation between prices and quantities and various first moments). Finally, a goodness of fit type measure relates these moments to their counterparts in the real data. This section reports estimates of our model using this basic procedure and undertakes an initial policy evaluation. ${ }^{16}$

B. Estimation with Price Uncertainty Only

In this subsection, we estimate our model assuming that cost variations are the only source of exogenous fluctuations. Under our assumption of competition (equivalently constant markups), variations in cost yield identical variations in new car prices. We chose not to use stochastic variations in the scrap value from the policy experiments for estimation purposes 
since these experiments occur in only a small part of the sample period. Further, with the model we have specified, variations in income play no role in the car market. ${ }^{17}$ The next section introduces other sources of fluctuations.

To implement this approach, we solve, using value function iteration, a stochastic version of the problem described in section II. That basic problem was modified in three ways. First, the price of new cars (c) is assumed to be stochastic. Second, the dynamic programming problem included an exogenous probability $(\delta)$ of a car wreck or breakdown. Second, individual iid taste shocks were added. Adding these features to the model are important for matching the hazard function for young cars: the wrecks imply a non-zero hazard at all ages and the idiosyncratic shocks imply an upward sloping hazard at all ages.

The modified dynamic programming problem is:

$$
\begin{gathered}
V_{i}(c, \epsilon)=\max \left[V_{i}^{k}(c, \epsilon), V_{i}^{r}(c, \epsilon)\right], \text { where } \\
V_{i}^{k}(c, \epsilon)=\epsilon\left(s_{i}+y\right)+\beta(1-\delta) E_{c^{\prime}, \epsilon^{\prime}} V_{i+1}\left(c^{\prime}, \epsilon^{\prime}\right)+\beta \delta\left(E_{c^{\prime}, \epsilon^{\prime}} V_{1}\left(c^{\prime}, \epsilon^{\prime}\right)+\pi-c^{\prime}\right), \\
V_{i}^{r}(c, \epsilon)=\epsilon\left(s_{1}+y+\pi-c\right)+\beta(1-\delta) E_{c^{\prime}, \epsilon^{\prime}} V_{2}\left(c^{\prime}, \epsilon^{\prime}\right)+\beta \delta\left(E_{c^{\prime}, \epsilon^{\prime}} V_{1}\left(c^{\prime}, \epsilon^{\prime}\right)+\pi-c^{\prime}\right) .
\end{gathered}
$$

For this specification, the taste shock $\epsilon$ creates variation in the value of total consumption $\left(s_{i}+c\right)$ today relative to the future. In the first option of this problem, the agent chooses to keep the age $i$ car and has a current period utility flow of $\epsilon\left(s_{i}+y\right)$. With probability (1- $\left.\delta\right)$, the agent has a car of age $i+1$ in cost state $c^{\prime}$. With probability $\delta$, the car is wrecked at the end of the current period so that the agent scraps the car and buys a new one in the next period at a

\footnotetext{
${ }^{17}$ That is, we are estimating the parameters assuming that all variations in price come from, in effect, shifts in the supply curve rather than the demand curve. This is clearly a limitation of our framework and provides motivation for the more complete exercise that follows.
} 
price of $c^{\prime}$. In the second option, the agent scraps the age $i$ car and buys a new one in the current period which, as before, becomes an age 2 car in the next period or is wrecked and replaced. Note that in specifying this problem, we assume that any cars lost due to a wreck will be replaced: there is positive surplus to car ownership in all cost states.

For this specification, we focus on estimating $\gamma$, the preference parameter characterizing the mapping between the age of a car and its utility flow: i.e $s_{i}=i^{-\gamma}$ for $i=1,2$.., and $\delta$, the probability of car wrecks. The remaining parameters are taken from other sources. We set the discount rate at .95 , in accord with macroeconomic studies. Further, we set the scrap value of cars at 500F. To specify the transition matrix for new car prices in (13), we estimate an autoregressive equation for new car prices over the 1972-94 and compute a transition matrix for a 5-state Markov process for prices. We assume that the idiosyncratic taste shock took on five values between .9 and $1.1 .^{18}$

For moments, we use the times series means of the average age of automobiles and the fraction of cars 5 years old and less for small cars. We focus on small cars since these are most likely to be influenced by the policy-induced changes in scrap value.

Using this procedure, we estimated $\gamma=.08$ and $\delta=.08$. If we simulate our model for 500 periods at these parameter values, the average mean car age is about 6.2 years with $50 \%$ of the cars under age 5 . In the small car data over the 1972-94, the average age is 6.3 years and, on average, $50 \%$ of the cars are of age 5 or less. Thus, our model matches these means quite closely. These parameters are fairly precisely estimated. At $\gamma=.08$ and $\delta=.1$, average 
age falls to 6 and the fraction of cars under age 5 increases to $53.3 \%$. While at $\gamma=.1$ and $\delta=.08$, average age is only 5.3 and $57.5 \%$ of the cars are under age 5 .

For these values of the parameters, at the average value of new car prices and averaging across the taste shocks, cars are all replaced by age 19 and most are replaced by age 15. Our predicted hazard for small cars is flat at $8 \%$ until age 11 and increases until age 19 when the hazard is 1 . Our estimated hazard does show some sensitivity to prices. In the low price state, all cars are replaced at age 11 while in the highest price state, even some age 30 cars are not scrapped.

Given the parameter vector $\theta$, the recent Balladur-Juppé reforms can be evaluated in terms of our model. To do so, we must construct a stochastic version of the model to obtain the hazard functions associated with the various policy states. Here we emphasize the uncertainty associated with randomness in the scrap value of cars to mimic the scrapping subsidies. Thus we consider a version of (13) in which the cost of a new car is constant and there are no taste shocks but the scrap value is stochastic. ${ }^{19}$

Consider a three state model of the policy process with the transition matrix given below. In state 1 the scrap value is set at $5500 \mathrm{~F}$, the value assumed in the baseline model plus an additional payment of 5000F. This state is not assumed to be very permanent: there is only a $2 \%$ chance that the subsidy will be in effect in the next period conditional on being in force in the current period. In state 3 the scrap value is set at the baseline level. State 3 is relatively permanent. These two states are augmented by a third in which there are no subsidies but the

\footnotetext{
19 Note that for this exercise we hold the price of new cars fixed. The estimation and simulation in the next section allows for the joint evolution of these variahles.
} 
probability of subsidies arising in the near future is relatively high. Thus state 2 is one of heightened uncertainty.

Transition Matrix for $\pi$ state tomorrow

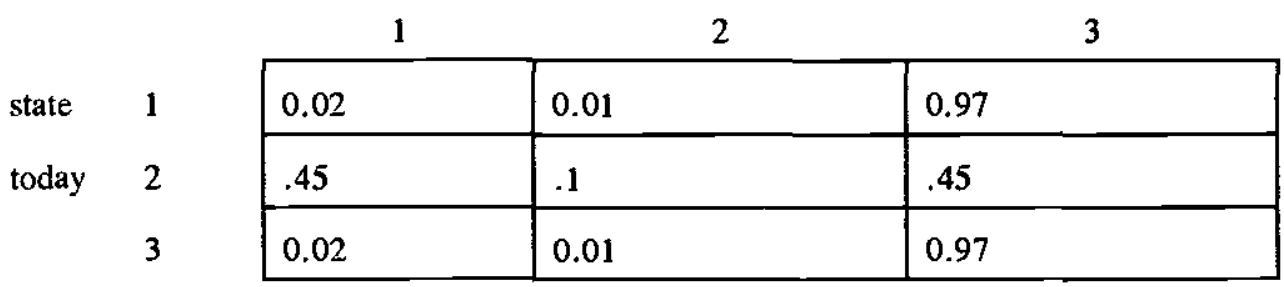

Given this transition matrix, a version of (13) is solved using the parameter estimates of $\gamma=.08$ and $\delta=.08$. The optimal scrapping times are quite responsive to these policies. In particular, the optimal scrapping age in state 3 (no subsidy) is 15 . This is the same as that reported for the stochastic price model for the average state. However, the optimal scrapping age in state 1 (subsidy available) is only 11 years. Finally, the optimal scrapping age is even higher (19) in state 2 than in state 3; a response by agents to the increased uncertainty associated with this state.

In order to simulate the Balladur-Juppé policy reform, the economy is given an initial cross sectional distribution corresponding to that observed in 1990 . Using the policy functions from the stochastic economy described above, a sequence of policies is fed into the model for 9 years. In particular, the realized states were $(3,3,3,3,1,2,1,3,3){ }^{20}$ Thus the subsidy policy is introduced in 1994 as almost a complete surprise. The policy is kept in place for one year. 1995 is a year of uncertainty and then the subsidy is introduced once again in 1996. It is

\footnotetext{
${ }^{20}$ From the perspective of the agents this is seen as a draw from the distribution of states used to create the stochastic hazard functions.
} 
finally removed in 1997. This sequence accords roughly with observations for France.

The simulated values of the sales rate and these policy states are given in Figure 7. Note the burst of sales following the introduction of the subsidy in 1994 . The sales burst is present but much smaller when the policy is introduced again in period 1996. This reflects the scrapping of cars that took place in 1994 leaving a distribution with relatively young cars in 1995. In fact, in our simulation the average age of cars starts at about 6 in period 1990, rises to 6.5 by 1994 and then falls to 4.7 in period 1995 (the period after the subsidy). Note too that there is an obvious slump in 1995 after the removal of the subsidy and the ensuing uncertainty. This reduction in sales also reflects the change in the cross sectional distribution stimulated by the subsidy. In fact, if 1995 had been state 3 rather than 2 , sales would not have been different since the stock of cars in 1995 was so young.

Relative to the experience in France, our model certainly captures the burst of sales in 1994 through June 1995 indicated in Figure 1. From June 1995 to September 1995, no subsidy was in place and, from Figure 1, actual sales were relatively low. The Juppé reform, started in September 1995 appears to have had a smaller effect on sales than the Balladur reform. Further, the average age of cars increased during the 1990-94 period: it rose from 6.0 in 1990 to 7.3 in 1994 . This pattern is similar to that produced by the model.

Figure 8 shows the longer run effects of the policies where we assumed the policy was in state 3 after 1998. Note that the burst of sales that appear in 1994 and 1996 reappear about 15 years later though the subsequent sales peaks are smaller. ${ }^{21}$ Essentially, the random

\footnotetext{
${ }^{21}$ Recall that in the middle price state without policy intervention, cars are replaced every 15 years.
} 


\section{Simulation of Scrapping Policy .}

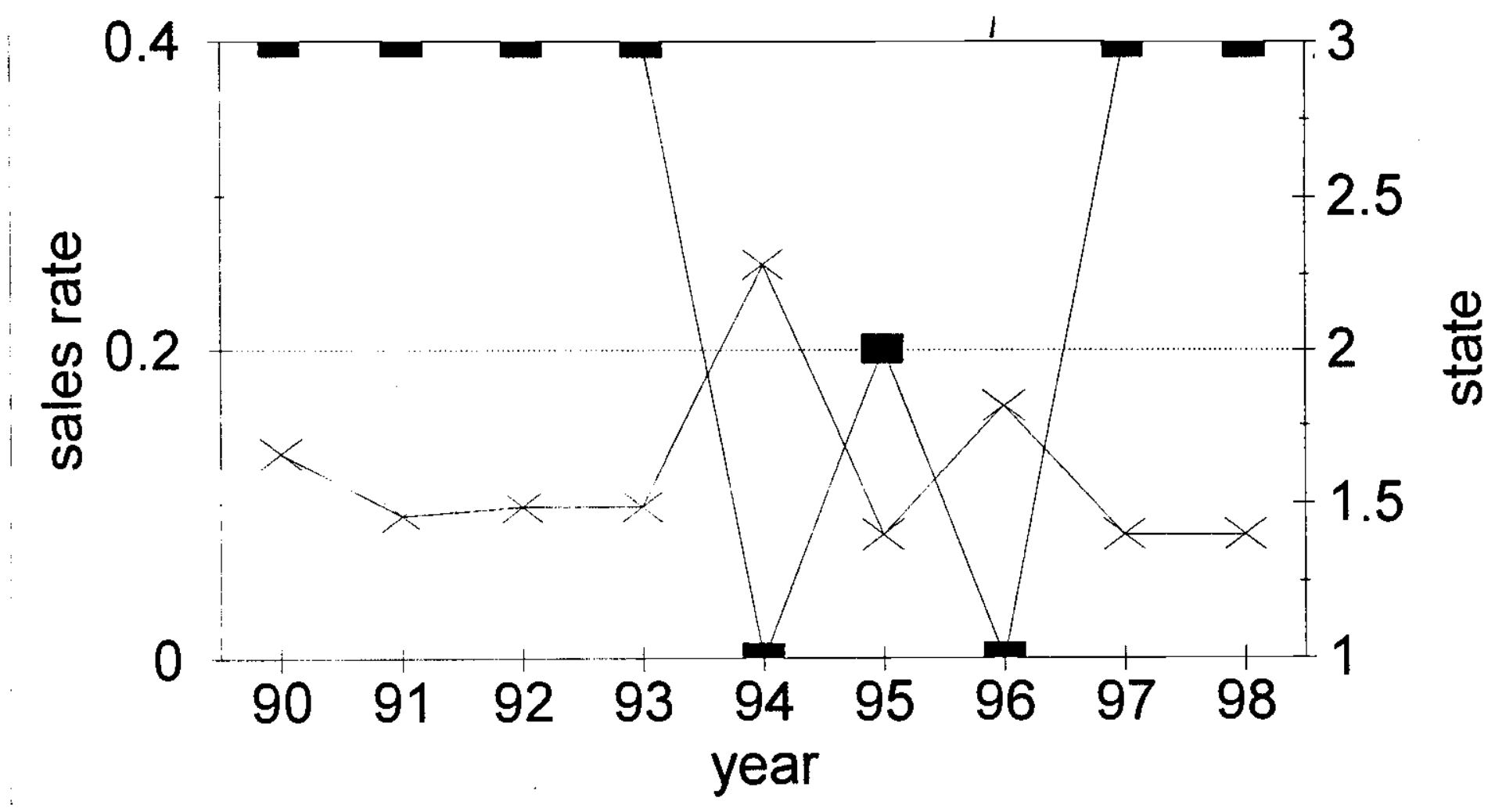

Figure 7 


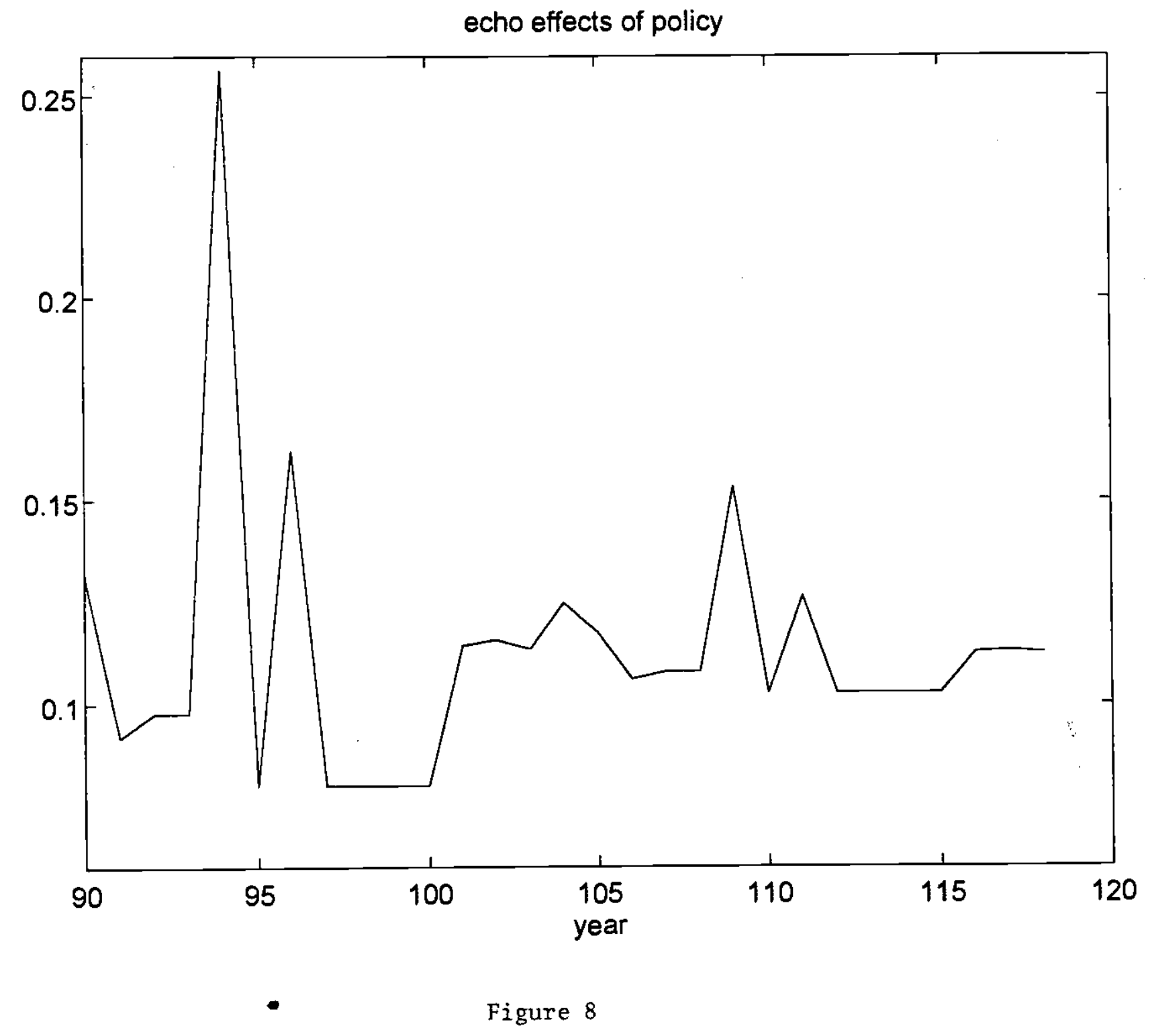


depreciation of the cars implies that the echo effects get smaller as time passes.

Figure 9 shows the impact of the policy on government revenues relative to a baseline simulation in which there are no realized policy interventions (though agents beliefs were governed by the transition matrix given above). This baseline was contrasted with the intervention described earlier. To calculate government revenues from the market, note that the current VAT yields about $12,000 \mathrm{~F}$ per new car sale and the subsidy was assumed to be $5,000 \mathrm{~F}$. Thus for each car that is scrapped and replaced by a new car, the government earns $7,000 \mathrm{~F}$. These gains under the interventionist policy must be weighed against the revenues the government would have received in the absence of the scrapping subsidy, 12,000F per car, times the number of cars. Essentially, this is a Laffer curve type argument: does the tax base rise enough as the net tax rate falls so that total government revenues rise?

From Figure 9 it appears that in the short run government revenues are about $40 \%$ higher under the policy than the baseline. However, these revenues gain are very short lived: revenues are below the baseline for all subsequent years including the second subsidy period.

\section{Estimation of a Complete Stochastic Model}

In this section we generalize the model to incorporate stochastic income. To the extent that fluctuations in income influence durable purchases, as suggested by much of the empirical work on durables, our probit analysis and the evidence presented by Greenspan-Cohen [1996], the model in the previous section is incomplete.

In the modified model, the agent earns an income which can be decomposed into two parts, an aggregate component $(\mathrm{Y})$ and an idiosyncratic one $(\mathrm{y})$. Thus, there are two sources of heterogeneity at the individual level, the age of the car and idiosyncratic income. 


\section{Government Revenues Ratio of Policy to Baseline}

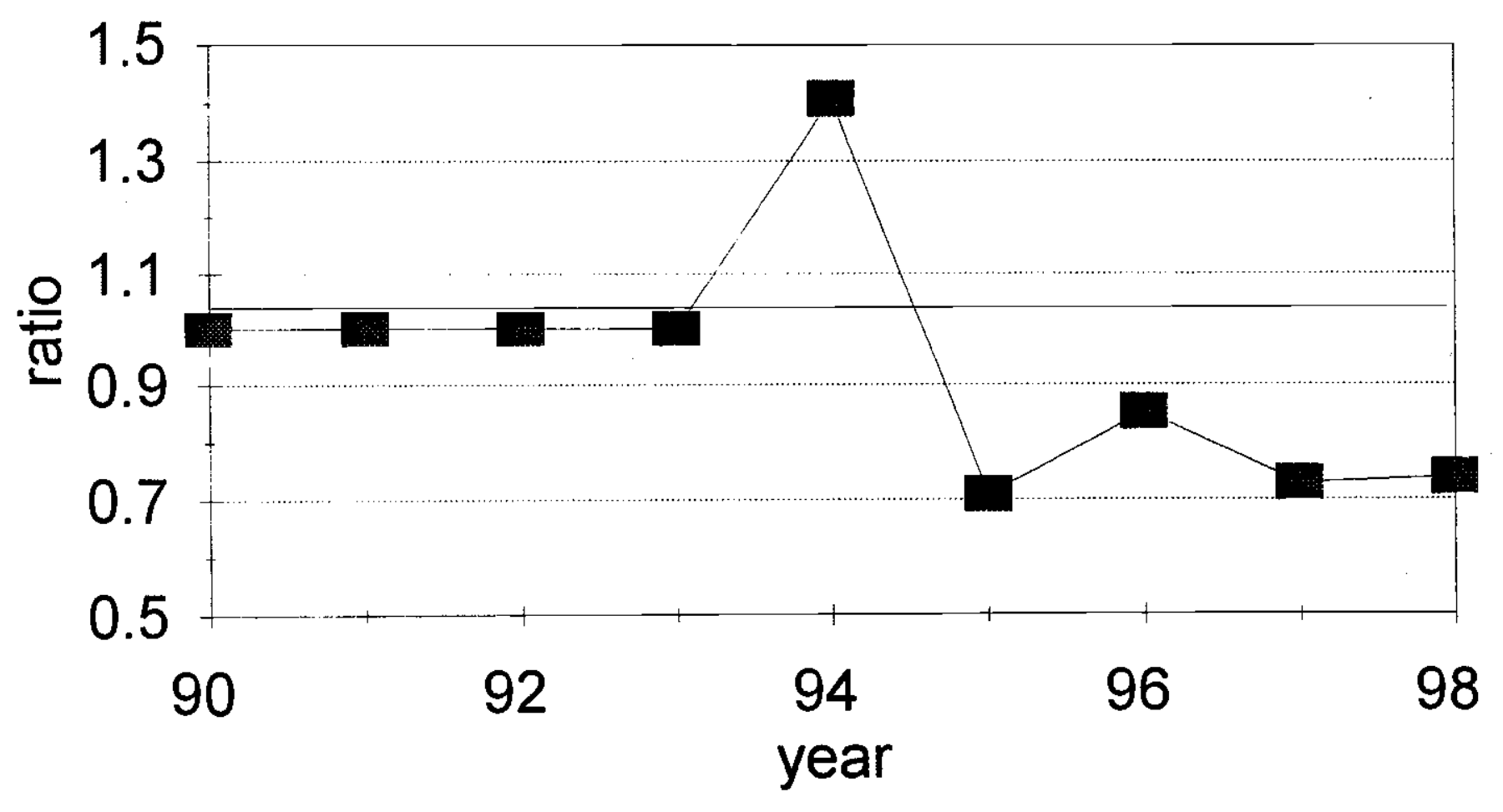


Note that in order for income variations to matter, the preferences of the representative agent must be altered. In particular, we consider a specification in which utility over the service flow from an age $i$ car and nondurable consumption (C) is

$$
u\left(s_{i}, C\right)=i^{-\gamma}+\frac{(C / \lambda)^{1-\xi}}{1-\xi}
$$

where $\lambda$ is a scale factor between services of cars and $\mathrm{C}$.

Finally, in this section we consider more the broader empirical implications of our model. In particular, the previous exercise focused on time series means since, with income fluctuations excluded, we were not able to explain much of the time series variation. Here, with a richer stochastic structure, we consider an overidentified empirical model and attempt to match the implications of our theory against a larger set of moments.

The dynamic programming problem for the individual is given by:

$$
\begin{gathered}
V_{i}(z)=\max \left[V_{i}^{k}(z), V_{i}^{r}(z)\right], \text { where } \\
V_{,}^{k}(z)=e^{\epsilon} u\left(s_{i}, Y+y\right)+\beta(1-\delta) E V_{i+1}\left(z^{\prime}\right)+\beta \delta E\left[V_{1}\left(z^{\prime}\right)+e^{\epsilon^{\prime}} u(1, Y+y+\pi-c)-e^{\epsilon^{\prime}} u(1, Y+y)\right], \\
V_{i}^{r}(z)=e^{\epsilon} u\left(s_{1}, Y+y+\pi-c\right)+\beta(1-\delta) E V_{2}\left(z^{\prime}\right)+\beta \delta E\left[V_{1}\left(z^{\prime}\right)+e^{\epsilon^{\prime}} u\left(1, Y+y+\pi-c^{\prime}\right)-e^{\epsilon^{\prime}} u(1, Y+y)\right] .
\end{gathered}
$$

where $z \equiv(Y, y, c, \epsilon)$ represents the current state and the expectation is taken with respective to $z^{\prime}$ conditional on $z$. Note that we do not allow our agents to borrow and lend: i.e. wealth is not a state variable. Hence, this specification introduces a role for income variations in an environment with severe credit restrictions. This contrasts with the previous section in which the assumption of linear utility meant that the smoothing of nondurable consumption was not 
an issue. ${ }^{22}$ Further, from (15), the incompleteness of markets implies that there is an additional cost to the scrapping/purchase choice: $e^{e^{\prime}}\left[u\left(1, Y+y-c^{\prime}+\pi\right)-u(1, Y+y)\right]$.

\section{A. Estimation}

We assume that the idiosyncratic part of income $(y)$ is a zero mean iid normal variable with variance $\sigma_{\mathrm{y}}{ }^{2}$. The aggregate part is modeled as an autoregressive process, as aggregate income appears to be very persistent. More precisely, as aggregate income and prices are correlated, we model the joint process as a VAR(1) model with autocorrelated innovations. We assume that the taste shock is normally distributed with zero mean and constant variance $\sigma_{\varepsilon}{ }^{2}$. To ease the computation of the value function, we discretize all the state variables and construct a Markov approximation (see Tauchen and Hussey [1991] for the univariate case). Income and prices thus follow a bivariate Markov process which mimics a VAR(1) process.

The estimation is done in two steps. In the first step, we estimate a VAR model for aggregate income and car prices and compute the optimal grid values for income and prices, as well as the transition matrix for these two series. ${ }^{23}$

In the second step, we estimate the structural parameters $\theta=\left(\gamma, \xi, \lambda, \delta, \sigma_{y}, \sigma_{\epsilon}\right)$ using a simulated method of moments. For a given vector of parameters $\theta$, and an initial cross section distribution, we simulate a path for the aggregate taste shock over the period 1972:1994. Over that period, we observe the realization of aggregate income and prices. Using (13), we can construct the predicted cross sectional distribution over that period and match it against the

\footnotetext{
${ }^{22}$ An intermediate model with curvature in the utility function and perfect capital markets is beyond the scope of this paper since it would add an additional state variable to the analysis. See Carroll-Dunn [1997] for some recent work in this direction on housing. Grossman-Laroque [1990] provides the foundation for an analysis with weatth when the stock of durables is continuous.

${ }^{23}$ The results from this exercise are availabie from the authors.
} 
actual one. If $\mathrm{X}$ is a (Txk) matrix of $\mathrm{k}$ observed series of length $\mathrm{T}$, and $\tilde{X}(\mathrm{Y}, \mathrm{P}, \epsilon, \theta)$ is a (Txk) matrix of predicted values, we use the following moment equation to estimate $\theta$ :

$$
f(X)-E_{\epsilon}\left[f\left(\tilde{X}\left(\epsilon, \theta_{0}\right)\right)\right]=0
$$

where $f(\cdot)$ is a ( $q \times 1)$ function of data, with $q$ the number of moments to match. Empirically, the optimal vector of parameters is the solution to

$$
\theta=\operatorname{argmin}_{\theta}\left[f(X)-\frac{1}{N_{\epsilon}} \sum_{n=1}^{N_{c}} f\left(\tilde{X}\left(Y, P, \epsilon^{n}, \theta\right)\right)\right]^{\prime} W_{T}^{-1}\left[f(X)-\frac{1}{N_{\epsilon}} \sum_{n=1}^{N_{\epsilon}} f\left(\tilde{X}\left(Y, P, \epsilon^{n}, \theta\right)\right)\right]
$$

Given the vector $\mathrm{P}$ of realized prices and the vector $\mathrm{Y}$ of realized income, we draw $\mathrm{N}_{\epsilon}$ vectors of aggregate shocks from the centered normal distribution with variance $\sigma_{\epsilon}^{2}$. Note that for each iteration of the estimation procedure, we have to compute the value function and the aggregate hazard function, which considerably slows the computation. ${ }^{24,25}$ The weighting matrix $\mathrm{W}_{\mathrm{T}}$ is constructed as $\mathrm{W}_{\mathrm{T}}=\left[\left(1+1 / \mathrm{N}_{\epsilon}\right) \Xi\right]$, where $\Xi$ is a heteroskedastic and autocorrelation consistent covariance matrix as presented in Newey and West [1987]. Under standard regularity assumptions, the estimators are asymptotically consistent for $\mathrm{N} \epsilon$ fixed.

The choice of a set of moments is crucial. Let Frac $_{\mathfrak{i l}}$ be the fraction of cars aged $i$ or less. We concentrate on the means and variance of the series $\left(\operatorname{Frac}_{i j}\right), i=\{1,5,9,11,15\}$ as well

\footnotetext{
${ }^{24}$ As the idiosyncratic shock is discretized, for small variations in the parameters, the optimal scrapping age for the selected individuals does not vary. Thus optimizing methods based on gradient search will fail to find an optimum. Therefore we use a simulated annealing method. For any technical explanations, we refer the reader to Goffe et al. [1994]. The computation of the standard errors were done by smoothing the objective function using polynomial functions of the parameters. To avoid colinearity when using higher order terms, we used Chebychev polynomials to form an orthogonal basis.

${ }^{25}$ The estination was done with $N \epsilon=100$, three states for income and prices, as well as two states for the aggregate shock. With this setting. the estimation took about 8 days on a Sun Spark 20 workstation.
} 
as those of the mean age of the cars. We also include the covariances between Frac ${ }_{1 \mathrm{t}}$ (aggregate sales) and $\mathrm{Frac}_{\mathrm{it}-1}$, between $\mathrm{Frac}_{1 \mathrm{t}}$ and aggregate income and between Frac $1 \mathrm{t}$ and prices. We expect that the covariance between prices and aggregate sales will be difficult to match as the model assumes constant marginal cost and is thus unlikely to create the positive correlation observed in the data. This gives 15 moments to match with 6 parameters : the system is over-identified.

The results are presented in Table 2. The estimated parameters are quite sensible. The curvature for nondurable consumption is close to 2 , a standard value for CRRA utility functions. The parameter characterizing the service flow from cars is .02 , which is much lower than our earlier estimate. ${ }^{26}$ The breakdown probability $(\delta)$ is estimated at $7 \%$, which seems reasonable and is quite close to the estimate presented in the previous subsection. The variance of the idiosyncratic income is close to $60,000 \mathrm{~F}$. For comparison, over the observed period, the standard deviation of French income is about 90,000 F from micro data. Finally, the standard deviation of the aggregate taste shock is relatively small, indicating that most of the variance of the data is captured by income and price movements. However, a test of the over identifying restrictions rejects the model. As expected, the covariance between prices and sales is very difficult to match. The standard errors are relatively high, which is not unexpected given the short size of our data sample and our discretization. However, the breakdown probability is significant.

To further evaluate our estimates, we look at the price implications of our model. In

\footnotetext{
${ }^{26} \mathrm{This}$ is somewhat surprising since the curvature in utility effectively increases the cost of replacement and thus increase average age. Thus one might conjecture a higher $\gamma$ to counteract this effect.
} 
particular, consider age specific prices such that the average agent (in terms of income and tastes) is indifferent between keeping and selling a car. These prices are obtained by solving a non-linear version of equation (3). Once the path of prices has been calculated, we estimate a "depreciation rate", denoted by $\tau$, modeled as $\ln \left(\mathrm{p}_{\mathrm{i}} / \mathrm{p}_{1}\right)=-\tau i$ where $\mathrm{i}$ denotes car age. The parameter $\tau$ is estimated at $0.22(0.005)$ using French data. Using our simulated data we find a value of $0.21(0.08)$. These numbers are also comparable to the one estimated by Wykoff [1970] on US data. In this respect, the fit of the model appears quite satisfactory.

A second check of the estimates is to relate the predictions of our model to a time series representation of new car sales. Following Mankiw [1982], under the hypothesis of quadratic preferences, income uncertainty and durable goods, these expenditures $\left(e_{v}\right)$ follow an $\operatorname{ARM} A(1,1)$ model:

$$
e_{t, 1}=\delta a_{0}+a_{1} e_{t}+u_{t+1}-(1-\delta) u_{t} \text { with } a_{1}=\beta(1+r)
$$

where $\delta$ is the physical depreciation rate. We estimate this equation on the sales of new cars, annually, in order to estimate the MA coefficient, and thus $\delta .^{27}$ We also simulate new car sales from our model ( using the estimated parameters) over the same number of periods. In order to avoid spurious results from a particular draw of the stochastic shocks, we simulate the sales of new cars for 100 different paths for prices and income. We then estimate the ARMA $(1,1)$ model on the data created by the simulation. The results are displayed in Table 3.

For the annual data, we find similar results to those reported in Mankiw [1982]: $\delta$ is

\footnotetext{
"The data show a significant trend, as the sales of new cars is growing over the time period. Mankiw estimates this equation without any time trend. In order to have comparable results. we provide the estimation with and without a trend polynomial.
} 
abnormally high, almost close to one, which implies that the good is not durable at all. Accounting for trends lower the estimate only slightly. The results are qualitatively the same when more lags are allowed in the moving average.

Caballero [1990,1993] argues that the adjustment dynamics are better captured in a discrete choice structure. Our approach is to compare the MA coefficient from simulated data (again using our estimated parameters) with estimates from the actual data. From Table 3, the time series implications of the aggregated discrete choice model are quite close to estimates from French data. So, the discrete choice structure, with its emphasis on the evolution of the cross section distribution, captures quite well the time series of new automobile sales.

B. Policy Evaluation

We embellish our earlier analysis and consider four states for the policy analysis. In State 1 the scrap value is set at $5500 \mathrm{~F}$ for cars older than 10 years as in the Balladur policy period. In State 2, the scrap value is also $5500 \mathrm{~F}$ but for cars older than 8 years old as in the Juppé subsidy. State 3 is a state of heightened uncertainty, in which there are no subsidies. In State 4 the scrap value is set at the baseline value $(500 \mathrm{~F})$. The matrix is qualitatively similar to that used before and was set as:

Transition Matrix for $\pi$

\begin{tabular}{|c|c|c|c|c|c|}
\hline & & & e tomo & & \\
\hline & & 1 & 2 & 3 & 4 \\
\hline state & 1 & 0.01 & 0.01 & 0.01 & 0.97 \\
\hline today & 2 & 0.01 & 0.01 & 0.01 & 0.97 \\
\hline & 3 & 0.225 & 0.225 & 0.1 & 0.45 \\
\hline & 4 & 0.01 & 0.01 & 0.01 & 0.97 \\
\hline
\end{tabular}


Using this transtition matrix and the parameter estimates from the general model with taste, income and price shocks, we again solve the dynamic programming problem with a stochastic scrap value. Consider the four hazard functions evaluated at the mean states for the price, income and taste shocks. Under the estimated parameterization, there is a discrete jump in the hazard functions at age 10 under the Balladur reform, as well as a jump at age 8 for the Juppé reform. State 3 is characterized by a lower hazard function as households have an option to wait until the uncertainty is resolved at the next period. From our experience, the results are again not very sensitive to the calibration of the transition matrix.

We simulate the model using these hazard functions and taking the 1993 cross sectional distribution as an initial condition. Assume that the realized states for the scrap value were $(4,1,3,2,4,4, \ldots, 4)$, starting in 1993. As in the previous analysis, the subsidy is introduced in 1994 as almost a complete surprise and is kept in place for one year. This is followed again by a period of uncertainty and then the introduction of the Juppé policy. As a baseline, we also simulate an economy without any tax credit policies (i.e.state 4 occurs in every period), with the same draws of prices and income as above.

We conducted two experiments. The first one is an ex ante analysis: Given the state of income and prices in 1993 and the dynamic of these series, what are the expected sales and government revenue? This is the question that the Balladur government presumably analyzed before setting up the policy. The second takes an ex post perspective: What are the predictions of the model given realized income and car prices from 1993 to 1996 ?

For the first exercise, we performed Monte Carlo simulations over the paths of prices 
and income to calculate the expected (dated 1993) aggregate sales. ${ }^{28}$ Aggregate sales under the two regimes are presented in Figure 10.

Note the burst of sales following the introduction of the subsidy in 1994 and 1996. In 1995, there is a slump, as cars are younger in the economy and there is increased uncertainty. Our simulations indicate that following the 1994 subsidy, the average age of cars falls by about $2 \%$ relative to baseline, and by $4 \%$ for the Juppé reform. After 1996 , the expected new sales remain lower relative than the baseline, as the cars are younger. This lasts about 13 years after which there is a slight increase in the number of new cars, as the generation of cars from the policy reforms are scrapped.

Figure 11 shows expected revenues of the government relative to the baseline. The path of government revenues follow the path of aggregate sales. Note that here we do observe government revenues rising above the baseline during the Juppé policy. After the two subsidy policies, it takes about 20 years to get back to the baseline value.

From the Monte Carlo study, we can derive the distribution of the long run revenues of the government. The long run value of government revenues relative to the baseline is calculated as the discounted difference between revenues under the policy and the baseline. The discounting factor is taken to be $8 \% .{ }^{29}$ The distribution of expected long-run income is shown in Figure 12.

On average this number is negative, at about -1 billion French francs $(-200$ million

\footnotetext{
:n The expectation was calculated on 1000 replications. Note that as the model is strongly non linear, this is not the same as taking an at erage uncome and price path. We lind significant differences. with the long run budget biased towards zero.

${ }^{29}$ This is the value used by the French Ministry of Finance in its calculations.
} 
Expected Aggregate Soles

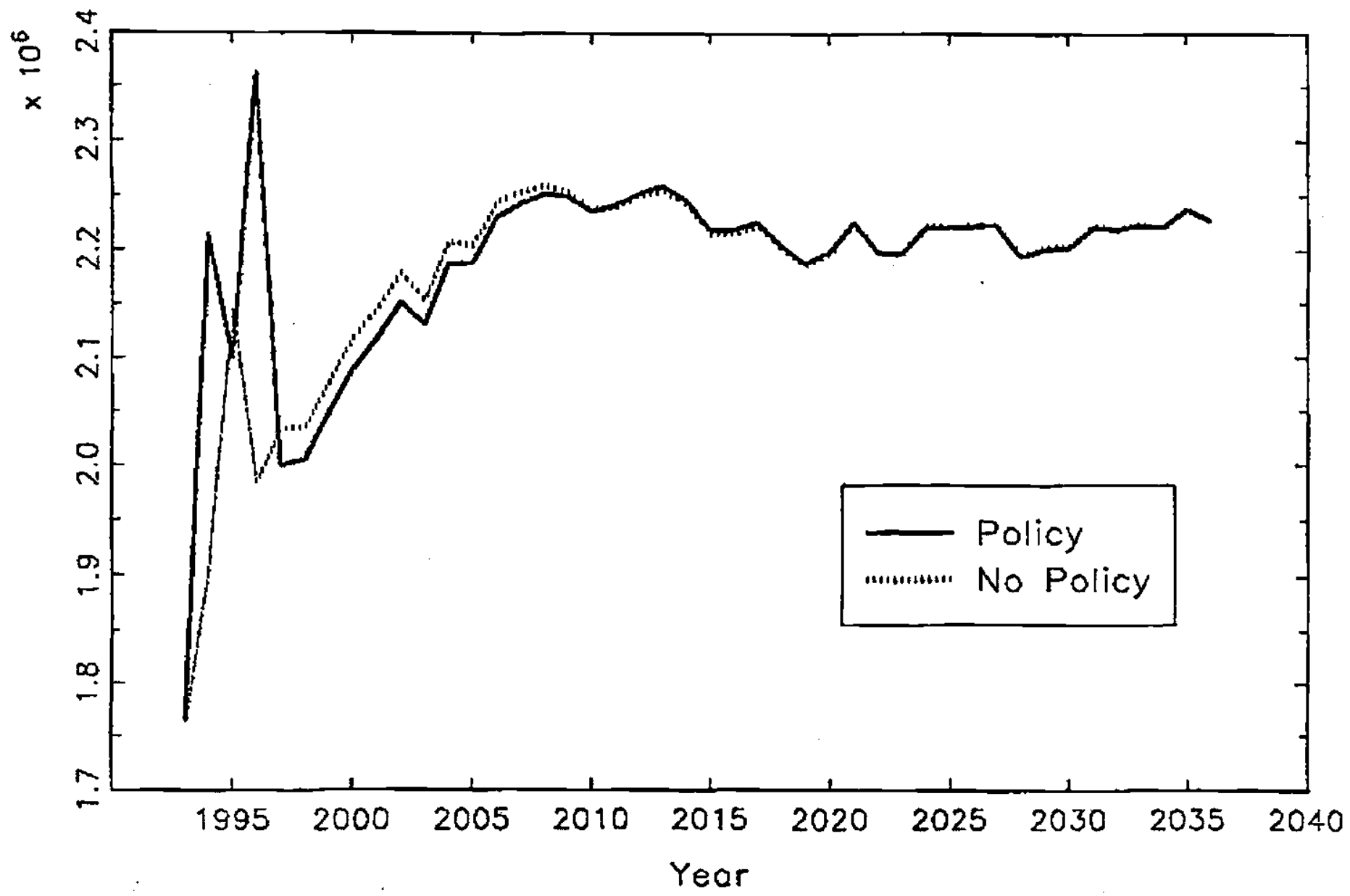

Figure 10 
Expected Government Revenues Relative to Boseline

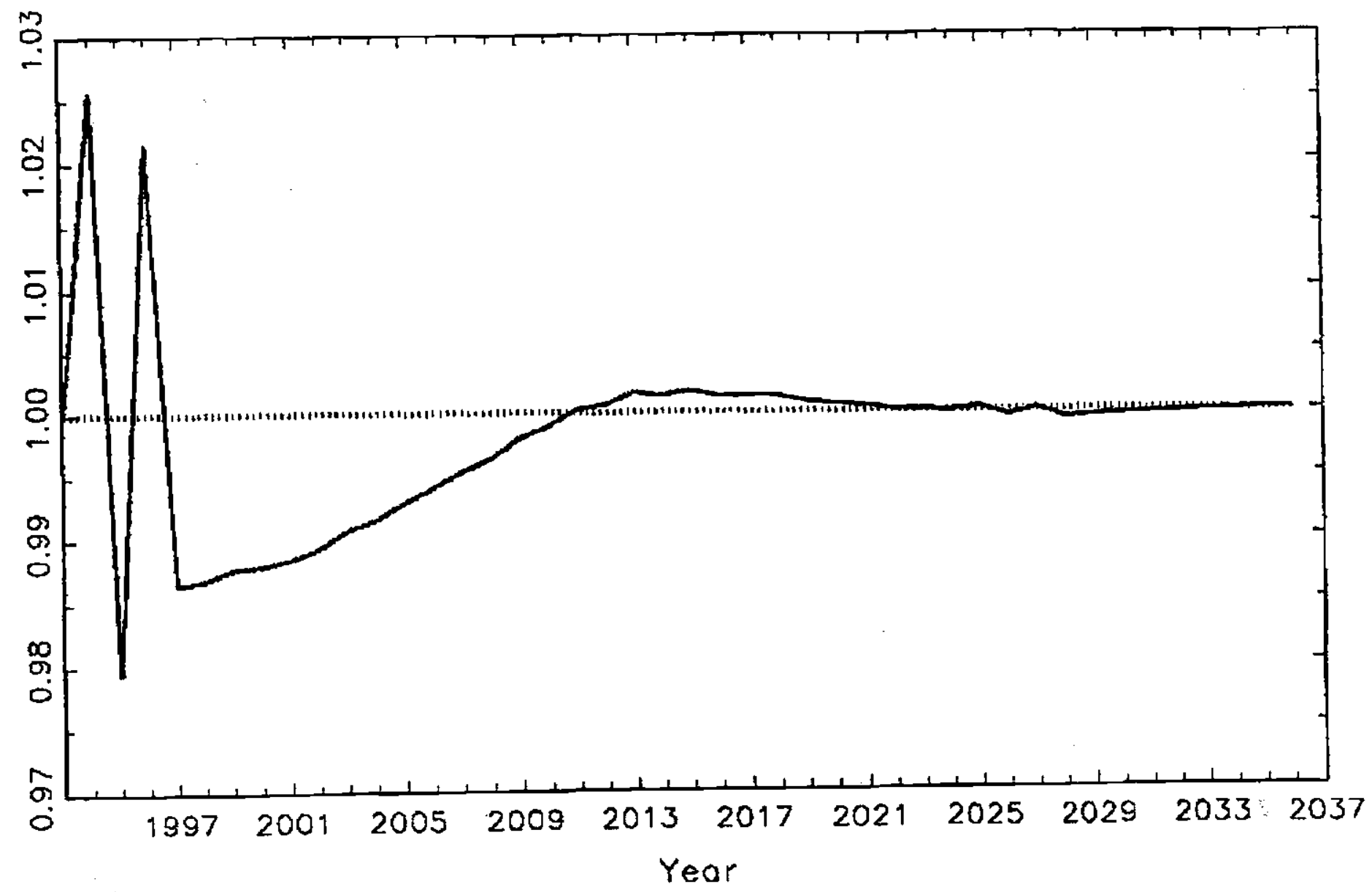

Figure 11 


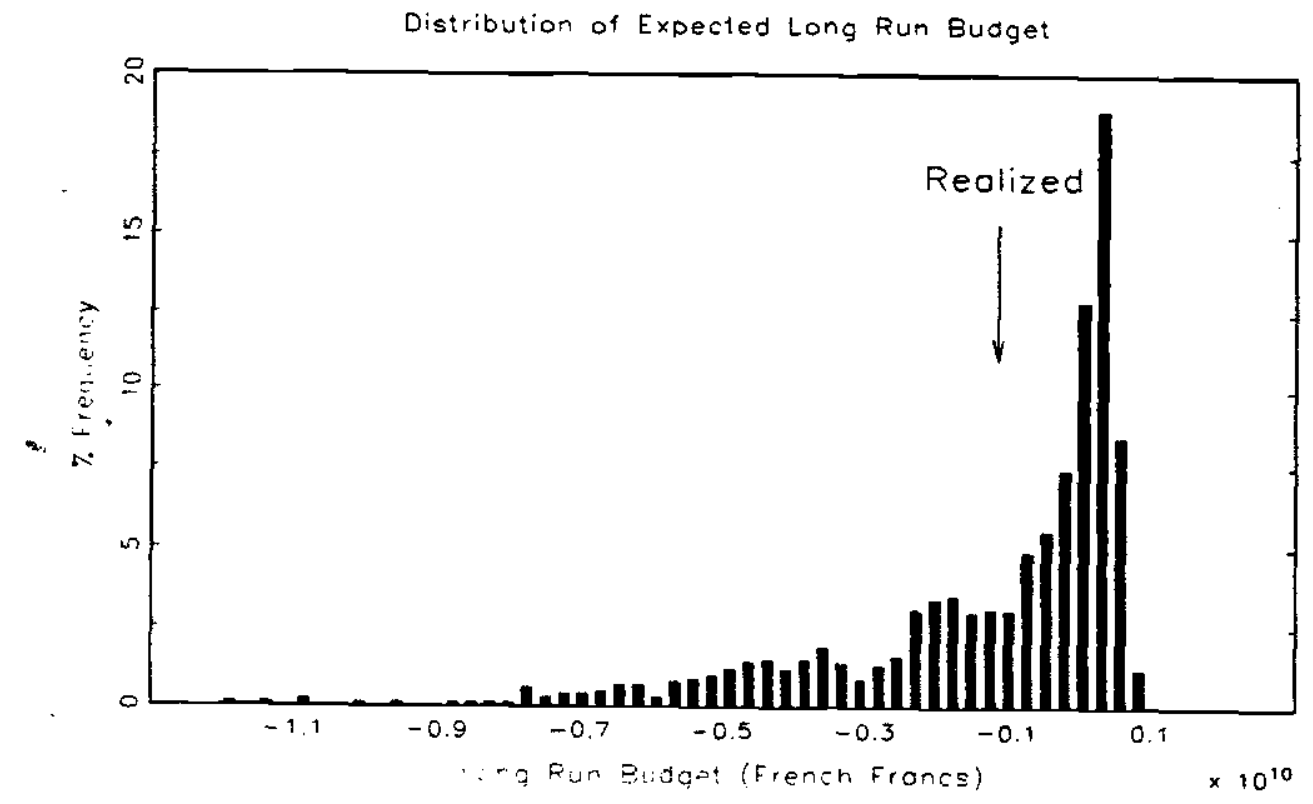

Figure 12: Distribution of Government Revenue 
dollars). However, there can be large variations and the standard deviation is about 2.43 billion francs. The distribution is skewed to the left. We found that, given the state in 1993 the government could expect the revenues to be negative in about $58 \%$ of the cases. This might be a reason for the increase in VAT in 1995 , from 18.6 to $20.6 \%$.

For the second experiment we fixed the prices and income at their value from 1993 to 1996. From 1996 onwards, the path of income and prices are drawn randomly. Qualitatively, the results are the same as above. The expected long run effect on the budget is evaluated at -.97 billion French francs. By using the realized income and prices from 1993 to 1996 , the fraction of subsidized cars is estimated at $23 \%$ and $28 \%$ which is very close to the $26 \%$ subsidization rate observed during the Balladur reform and the $31 \%$ rate observed during the Juppé policy. In terms of annual sales growth, the predicted figures from 1993 to 1996 are respectively $.25,-.05, .12$, whereas in the data, these figures are $.15,-.02, .1$. Our prediction for the sales during the Balladur reform are somehow overestimated, but for the remaining years, our predictions appears to be quite close.

\section{Conclusions}

The goal of this paper was to construct and empirically evaluate a discrete choice model of car purchases as a basis for policy analysis. We constructed an equilibrium model of the market for new and used cars that emphasized the discrete nature of ownership. The approach stresses the importance of the cross sectional distribution of car vintage in determining the flow of new cars produced.

The basic model was supplemented with a number of sources of uncertainty, at both the 
aggregate and individual levels. The dynamic programming problem in this expanded environment leads to a hazard function at the individual level. Aggregation across agents leads to fairly rich movements in aggregate sales. Using data on sales and moments from the cross sectional distribution of car vintages, we estimated our model by matching actual and predicted moments. For one exercise, we matched lower frequency averages and, for a second, the time series of sales and the cross sectional distribution.

Given the estimated parameters, the policy analysis was undertaken. Our approach highlights one of the important aspects of the use of tax credits for durable purchases as a stabilization tool: the initial effects of these policies are heavily dependent on the cross sectional distribution of car vintage. Further, the consequent evolution of the cross sectional distribution creates persistent effects of the policies. Consequently, policy analysis is much more difficult in this setting since the evolution of the cross sectional distribution must be taken into account. That said, our analysis illustrates that taking these dynamics into account is feasible and instructive for both the design and evaluation of policies. 


\section{References}

Attanasio, O. "Consumer Durables and Inertial Behavior: Estimation and Aggregation of $(\mathrm{S}, \mathrm{s})$ Rules," NBER Working Paper \#5282, Sept. 1995.

Bar-1lan, A. and A. Blinder, "Consumer Durables: Evidence on the Optimality of Doing Nothing, " Joumal of Money, Credit and Banking 24 (1992), 253-72.

Berry, S., Levinson, J. and A. Pakes, "Automobile Prices in Market Equilibrium," Econometrica, 63 (1995), $841-90$.

Bertola, G. and R. Caballero, "Kinked Adjustment Costs and Aggregate Dynamics" in NBER Macroeconomics Annual, vol. 5, ed. by O. Blanchard and S. Fischer, Cambridge, Mass.:MIT Press, 1990.

Boucekkine. R. and O. Licandro, "Replacement Echoes in Durable Purchases," mimeo, 1996.

Cahallero, R. "Expenditure on Durable Goods: A Case for Slow Adjustment," Quarterly Joumal of Economics, 105 (1990), 727-43.

"Durable Goods: An Explanation for Their Slow Adjustment, " Joumal of Political Economy, 101 (1993), 351-84.

Caballero, R. and E. Engel, "Explaining Investment Dynamics in U.S. Manufacturing: A Generalized (S,s) Approach", mimeo, December 1993.

Carroll, C. and W. Dunn, "Unemployment Expectations, Jumping (S,s) Triggers and Household Balance Sheets,"mimeo, Johns Hopkins University, 1997.

Cooper, R. and J. Haltiwanger, "The Macroeconomic Implications of Machine Replacement: Theory and Evidence," American Economic Review, 83 (1993), 360-82.

Cooper, R., J. Haltiwanger and L. Power, "Machine Replacement and the Business Cycle: Lumps and Bumps", NBER Working Paper $\$ 5260$, Sept. 1995

Eberly, J. "Adjustment of Consumers' Durables Stocks: Evidence from Automobile Purchases, " Jourmal of Political Economy, 102 (1994), 403-36.

Gautier, B. and J. Rouchet, "Prévision du marché automobile: estimation économétrique de la demande," Economie et Prévision, (1995).

Goffe, W.B., Ferrier G.D. and J. Rogers, "Global Optimization of Statistical Functions with Simulated Annealing" Journal of Econometrics, 69 (1994), 65-99.

Greenspan, A. and D. Cohen "Motor Vehicle Stocks, Scrappage and Sales," Finance and Economics Discussion Series. Federal Reserve Board, 1996-40.

Grossman, S. and G. Laroque, "Asset Pricing and Optimal Portfolio Choice in the Presence of Illiquid Durable Consumption Goods," Econometrica, 58 (1990), 25-51.

Lam, P. "Permanent lncome, Liquidity and Adjustments of Automobile Stocks: Evidence from Panel Data," Quarterly Journal of Economics, 106 (1991), 203-30. 
Lee, B.S. and B. Ingram, "Simulation Estimation of Time-Series Models, " Journal of Econometrics, 47 (1991), 197-205.

Mankiw, N. Gregory, "Hall's Consumption Hypothesis and Durable Goods," Journal of Monetary Economics, 10 (1982), 417-25.

Newey W.K. and K.D. West, "A Simple, Positive, Semi-Definite, Heteroskedasticity and Autocorrelation Consistent Covariance Matrix" " Econometrica, 55 (1987), 703-708.

Pakes, A. and D. Pollard, "Simulation and the Asymptotics of Optimization Estimators," Econometrica, 57 (1989) 1027-57.

Rust J. "Optimal Replacement of GMC Bus Engines: An Empirical Model of Harold Zucher", Econometrica 55 (1987), 999-1033.

Tauchen G. and R. Hussey "Quadrature-Based Methods for Obtaining Approximate Solutions to Nonlinear Asset Pricing Models" Econometrica, 59 (1991), 371-396.

Wykoff, F. "Capital Depreciation in the Postwar Period: Automobiles, "Review of Economics and Statistics, (1970), 168-72. 
Table 1

Probit Model for Replacing a Car

\begin{tabular}{|l|l|l|}
\hline Variable & Parameter Estimate & t-statistic \\
\hline Constant & -1.747 & -12.23 \\
\hline Age of car & .099 & 15.13 \\
\hline Age Squared & -.0022 & -6.04 \\
\hline Income & .1465 & 4.24 \\
\hline Income Squared & -.00367 & -1.35 \\
\hline Low Price S/S & .332 & 2.76 \\
\hline Low Price S/M & .455 & 3.7 \\
\hline Low Price S/L & .2077 & 1.6 \\
\hline Low Price M/S & .2251 & 2.09 \\
\hline Low Price M/M & .3894 & 3.52 \\
\hline Low Price M/L & .086 & .73 \\
\hline Low Price L/S & -.9699 & -7.94 \\
\hline Low Price L/M & -1.105 & -8.82 \\
\hline Low Price L/L & -.6468 & -4.88 \\
\hline
\end{tabular}

Notes: The explanatory variables include also year dummies, as well as dummies controlling for the size of the car, the age of head of household, the size of the household, the number of active members in the household. Low Price $i / j$ : dummy for low price of type $i$ new car and owning a type $\mathrm{j}$ car where $\mathrm{i}, \mathrm{j}$ are small, medium and large. 
Table 2

Estimated Structural Parameters

\begin{tabular}{|c|l|l|}
\hline Parameters & Estimates & Standard Errors \\
\hline$\gamma$ & 0.02139 & 0.018 \\
\hline$\xi$ & 1.63215 & 3.72 \\
\hline$\lambda$ & 381351 & 748457 \\
\hline$\delta$ & 0.072 & 0.016 \\
\hline$\sigma_{\mathrm{y}}$ & 61128.2 & 119111 \\
\hline$\sigma_{\varepsilon}$ & 0.0027 & 0.207 \\
\hline
\end{tabular}

Table 3

Evidence from Annual Car Sales

\begin{tabular}{|c|c|c|c|}
\hline \multirow{2}{*}{} & \multicolumn{2}{|c|}{ Annual Data } & \multirow{2}{*}{ Simulated Data } \\
\cline { 2 - 3 } & No trend & trend & \\
\hline$\delta$ & $0.97(0.23)$ & $0.66(0.35)$ & $0.8(0.43)$ \\
\hline
\end{tabular}

